\title{
ENHANCING THE ROBUSTNESS OF STEEL AND COMPOSITE BUILDINGS
}

\author{
D.A. Nethercot ${ }^{*}$, P. Stylianidis, B.A. Izzuddin and A.Y. Elghazouli \\ Department of Civil and Environmental Engineering \\ Imperial College, South Kensington Campus, London SW7 2BU, UK \\ *(Corresponding author: E-mail: d.nethercot@imperial.ac.uk)
}

\begin{abstract}
Methods intended for use in the design of steel and composite building frames covering the provision of adequate robustness so as to guard against progressive collapse are in the process of moving from prescriptive to quantitative. An approach that recognises all the important complex physical phenomena, employs a realistic criterion of failure and is capable of being implemented at a variety of levels has been devised at Imperial College London. Recent further development of this method has streamlined the necessary analyses, thereby making it possible to conduct parametric studies that provide insights into the link between changes to the structure and quantitative measures of resistance to progressive collapse. This approach is used herein to examine a number of different arrangements, from which key features of behaviour are identified. It has therefore been possible to isolate those structural modifications with the greatest potential for improving robustness and, moreover, to associate quantitative measures of that improvement with each scheme.
\end{abstract}

Keywords: Alternative load path, Column removal, Composite structures, Nonlinear static response, Parametric studies, Progressive collapse, Robustness, Simplified model

\section{INTRODUCTION}

Progressive Collapse of building structures is a topic that has come much to the fore in recent years. It does, however, have a chequered history - with its generally agreed genesis being the Ronan Point Collapse of 1968. This was followed by a somewhat fallow period characterised by Bruce Ellingwood's comment at the 1997 SEWC Conference in San Francisco:

"There is currently a virtual absence of research activity or interest in the United States in the topic".

and a recent surge of interest stimulated most notably by the World Trade Centre collapses in New York. But it is also possible to identify aspects of the topic in studies of WW2 bomb damage to structures in London, in measures designed to combat the IRA bombing campaigns and in various forensic studies on public safety issues that typically followed any major bomb blast on a significant structure e.g. the Murragh Building in Oklahoma City. As interest in the more scientific treatment of the topic has increased so also has the realisation that knowledge and evidence from adjacent fields e.g. seismic resistant design, can inform the process of developing strategies and procedures to better address a lessening of both the likelihood of a progressive collapse failure and the consequences should one be initiated.

This paper briefly reviews the current state of the art relating to both the development of a better understanding of progressive collapse and its treatment in design and then proceeds to present new developments in the Imperial College London approach, concluding with illustrative results for a range of cases of both steel and composite frames. These highlight certain limitations in existing design approaches. 


\section{POSSIBLE DESIGN APPROACHES}

The Ronan Point collapse demonstrated to the Structural Engineering Community in the UK the need for resistance to Progressive Collapse to become part of the routine design process for at least some types of structure. The absence of any basic theory meant that this could not follow the usual structural design approach of:

- Identifying a representative form of applied loading.

- Devising an analysis model from which to calculate structural response to this loading.

- Identifying key outputs from this analysis e.g. moments, stresses, deflections etc.

- Comparing the calculated values of these key outputs with suitable limits.

Instead, rather more indirect and essentially prescriptive approaches were devised. These fell into one of three types:

- Tying force.

- Alternate load path.

- Key elements.

Requiring that building frames be adequately tied together, including the specific requirement for steel frame structures that beam to column connections possessed a certain limited tying capacity (the ability to transmit an axial force from the beam into the column) should ensure greater robustness i.e. the ability that in the event of the structure suffering an incident for which it had not been specifically designed it would not suffer disproportionately. These concepts of robustness (a property of the structure) and disproportionate collapse (the initiation of progressive collapse) thus entered the vocabulary.

Tying has the advantage of being simple to appreciate, easy to implement through simple design calculations and being readily achievable in practice providing the required tying forces are not too large. Its main disadvantage is that it is entirely prescriptive in nature i.e. it is of the form "providing the provisions are satisfied behaviour will be better than if they are not", but there is no basis for comparing alternative arrangements nor for assessing the actual margin of safety against progressive collapse. Because of its simplicity, it has been widely, if not always correctly, used in the UK and has been introduced in other parts of the world as they too, developed design provisions against progressive collapse.

In the alternate load path approach a member is notionally removed and the ability of the damaged structure to resist some reduced level of applied load is then assessed. Most usual is column removal with the damaged floor(s) bridging over the increased span. The level of structural analysis used to examine the behaviour of the damaged structure varies from static applications using elastic theory and individual members to sophisticated numerical approaches including dynamic effects, large deformations and inelastic material behaviour. Clearly this approach entails more effort than does a simple application of the tying force approach; in return it provides information on the relative merits of different configurations and allows the designer to assess the effects of structural changes in a quantitative fashion.

In certain cases e.g. transfer girders, damage to a particular element would leave the structure with no alternate load path. Such members may be designed as "key elements", with their basic design being conducted to a larger load factor so as to provide a (supposedly) greater margin of safety to the structure. One of the most obvious key elements is the single spindle supporting the wheel of the London Eye; it is of considerable interest to read how the engineers responsible took into consideration the many features with the potential for unwanted consequences and rationalised their approach so as to provide an acceptably safe structural component. 
Clearly tying forces and key elements can only be regarded as prescriptive approaches yielding no information on the behaviour of the damaged structure and thus providing no insights into how a designer's knowledge of structural principles might be utilised in the search for the best solution to a given set of circumstances. Alternate load path analysis does, however, offer more possibilities particularly if it can be developed in a way that models the key features of progressive collapse whilst remaining tractable in terms of mathematical and computational complexity. It is, therefore, not surprising, that, particularly post WTC collapse, considerable effort has been focussed on developing and applying this approach, both by the research communities and by those responsible for deriving design rules.

Work conducted at Imperial College London during the past 5 years has been aimed at developing a complete design method - essentially based on the alternate load path concept of sudden column removal - that combines sufficient rigour that all essential physical features are correctly modelled with the simplicity of application necessary if it is to be attractive for use in practice. Its core is a quantitative assessment of the ability (or not) of the damaged structure to attain a new equilibrium position in its grossly deformed state. It incorporates dynamic effects (but without the need for dynamic analysis), allows for gross changes of geometry and inelastic material behaviour and recognises that the key governing property is the ability of the beam-to-column connections to deliver the necessary rotations.

Originally the analysis step was conducted using ADAPTIC [1] - although any suitable software package may be employed. The most recent advance is the possibility to use only "hand calculations" based on an extended slope-deflection approach suitable for the rapid examination of many alternative arrangements [2]. In parallel, work has also been conducted on modelling the behaviour of connections subject to the combined beam axial load plus moment forms of loading that arise during a progressive collapse [3].

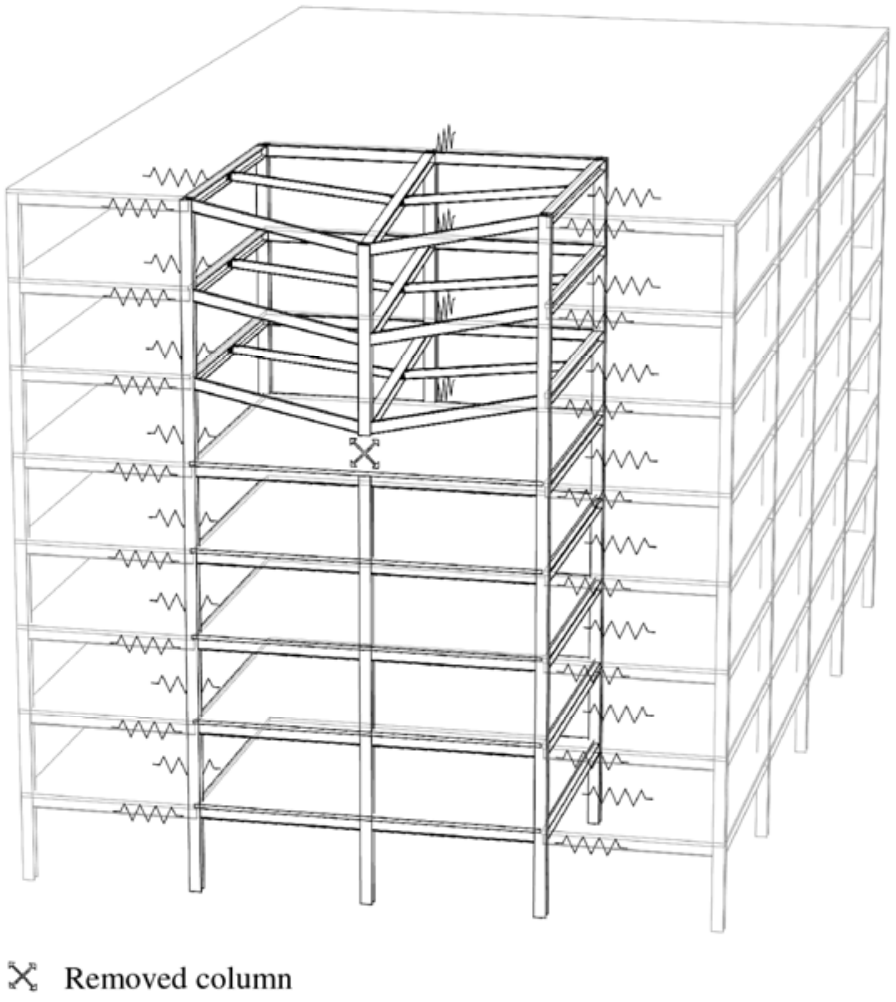

a. Full structure/affected bay

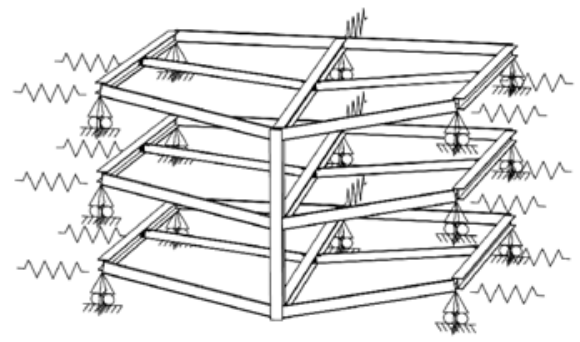

b. Multiple floor system

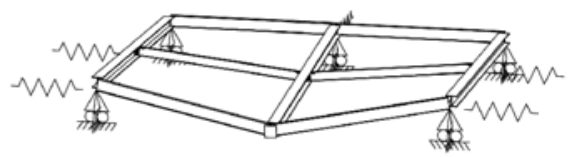

c. Single floor system

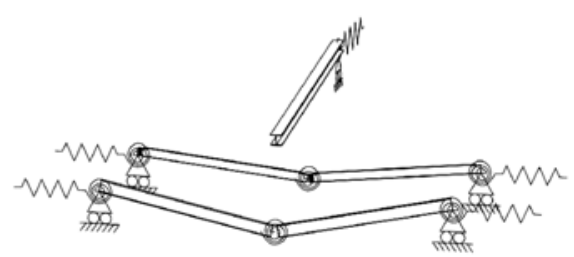

d. Individual beams

Figure 1. Simplified Multi-level Approach for Progressive Collapse Assessment 


\section{THE IMPERIAL COLLEGE METHOD}

Based on the sudden column removal scenario and the alternative load path concept, a complete design framework for progressive collapse assessment has been developed at Imperial College London $[4,5,6]$. The method is able to model the basic features of the problem and it offers the simplicity needed for routine use in practice.

The Imperial College method allows application at various levels of structural idealization via a simplified multi-level approach where implementation may be at member, affected floor, affected substructure or full structure as illustrated in Figure 1.

For removal of a peripheral column of the multi-storey building depicted in Figure 1a, the analysis can be limited to the affected bay provided the interaction with the surrounding structure is represented with suitable boundary conditions. Provided the remaining columns of the affected bay can resist the redistributed loading, the model can further be reduced to the number of floors above the removed column (Figure 1b). If these floors are identical in terms of structure and loading, their loading redistributions and responses are also identical and the model can be reduced to a single floor (Figure 1c). Finally, individual beam models can be considered if the slab membrane effect is ignored (Figure 1d).

The response at higher levels can be assembled from the responses at lower levels; therefore, the nonlinear static response at any level of structural idealization can be determined relatively easily. The nonlinear static response at the lower levels of structural idealization may be obtained by either detailed or simplified models.

However, since the actual response after sudden column removal is dynamic, the Imperial College framework proposes a simplified dynamic approach which transforms the static response under gravity loading to a dynamic response based on an energy equivalence concept. The resulting response is called pseudo-static and this simple approach eliminates the need for a detailed dynamic analysis. Finally, the dynamic capacity is obtained based on the available connection ductility.

\section{REPRESENTATION OF BEAM NONLINEAR STATIC RESPONSE}

As mentioned above, the nonlinear static response at the lowest level of structural idealization (i.e. individual beams) can be obtained by any type of analysis, thus by either detailed finite element or simplified analytical models. In this respect and in order to streamline the process, a simplified hand-calculation method for prediction of the beam nonlinear static response following column removal has been derived and is presented herein. The method is able to represent the basic features of beam behaviour such as material and geometric nonlinearity and connection bending moment-axial load interaction; it can be applied both in bare steel and composite arrangements.

Considering the double-span condition subject to removal of the intermediate column shown in Figure 2a, the response of a single beam can be modelled with the structural system depicted in Figure 2 b. In composite beams, a reduced cracked stiffness $\left(E I^{\prime}\right)$ is considered in the region of hogging bending moment. The model can be simplified by reasonably assuming a fixed point of inflexion at the mid-span $(L / 2)$. Beam deflection $(w)$ due to lateral loading $(q)$ is associated with beam bending, support axial deformation $\left(\Delta_{\mathrm{S}}\right)$ as well as rotation of the mid-span $(\Phi)$ and support $\left(\Phi^{\prime}\right)$ connections of the double-span beam as illustrated in Figure 2c. 


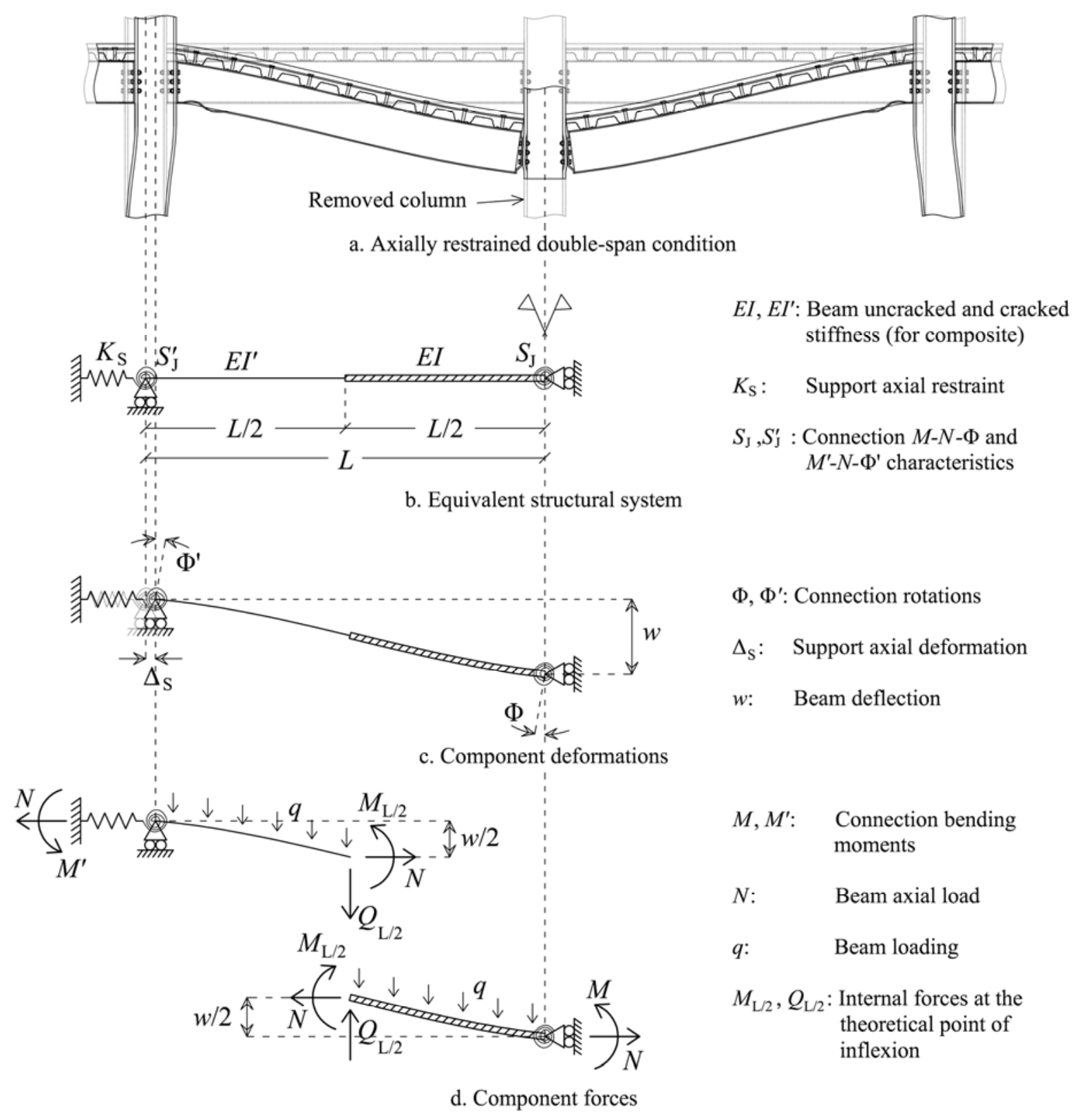

Figure 2. Representation of Beam Load-deflection Response Following Column Removal

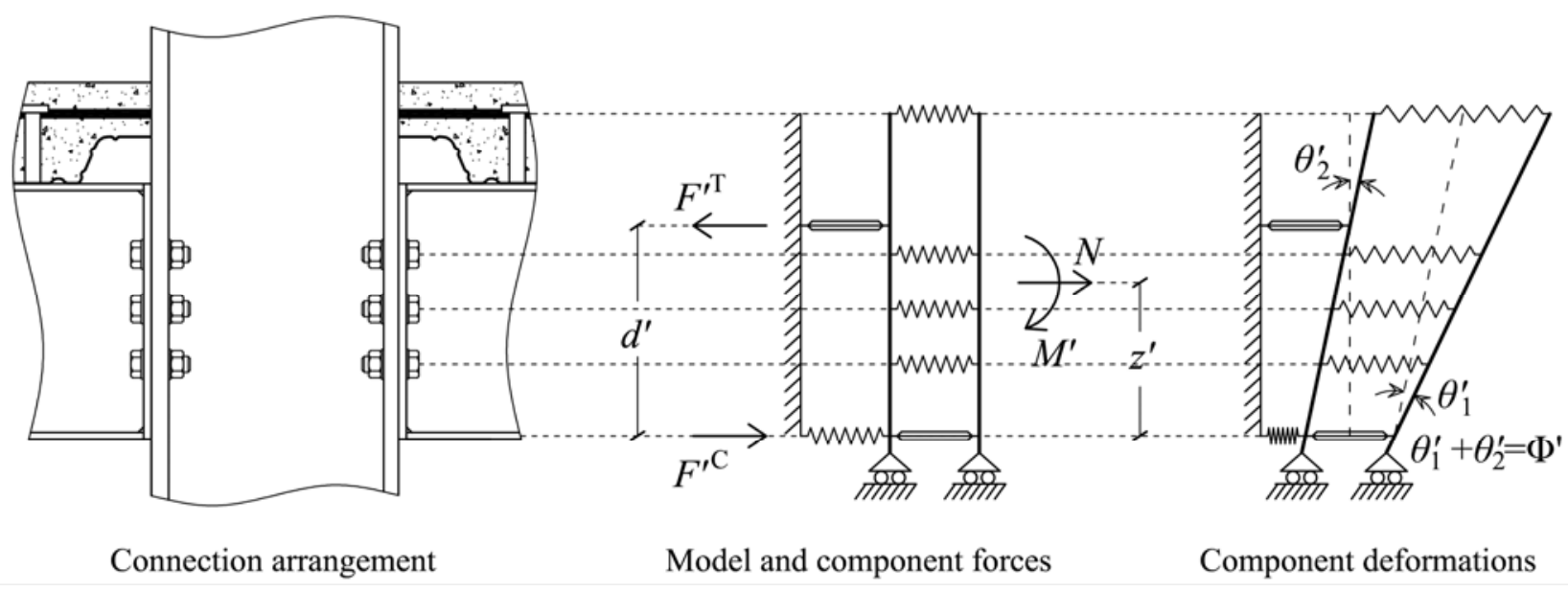

Figure 3. Connection Mechanical Spring Model 
Based on the mechanical spring model depicted in Figure 3 [7], the connection behaviour under combined bending moment $(M)$ and axial load $(N)$ has been explicitly studied [3]. The component method of EC3 [8] and EC4 [9] has been extended so as to incorporate the levels of axial load generated in column removal and the following connection bending moment-axial load-rotation relationship has been developed [3]:

$$
\begin{aligned}
& \Phi=M \alpha_{1}+N z \beta_{1}-\gamma_{1} \\
& \Phi^{\prime}=M^{\prime} \alpha_{1}{ }^{\prime}+N z^{\prime} \beta_{1}{ }^{\prime}-\gamma_{1}{ }^{\prime}
\end{aligned}
$$

where the parameters $\alpha_{1}, \beta_{1}, \gamma_{1}$ and $\alpha_{1}^{\prime}, \beta_{1}^{\prime}, \gamma_{1}^{\prime}$ are associated with the geometric and material properties of the mid-span and support connections respectively, whereas $z$ and $z^{\prime}$ correspond to the level of application of $N$, measured from the centre of compression of each connection respectively.

For the structural system depicted in Figure 2, the mid-span and support connection bending moments $\left(M, M^{\prime}\right)$ as well as the bending moment at the theoretical point of inflexion $\left(M_{\mathrm{L} / 2}\right)$ are determined by the sum of the equivalent nodal forces of the corresponding clamped structure (Figure 4a) and the nodal forces caused by the deformations of the corresponding released structure (Figure $4 \mathrm{~b}$ ) according to the stiffness method. By substituting the resulting expression for $M_{\mathrm{L} / 2}$ into the equilibrium equations of the two sections shown in Figure $2 \mathrm{~d}, \Phi_{\mathrm{L} / 2}$ and $w_{\mathrm{L} / 2}$ can be expressed in terms of the remaining parameters. By substituting $\Phi$ and $\Phi^{\prime}$ from Eq. 1a and Eq. $1 \mathrm{~b}$ respectively and solving the resulting set of equations for $M$ and $M^{\prime}$, the relationships between the connection bending moments, the beam axial and lateral load and the beam deflection are obtained as follows:

$$
\begin{aligned}
& M=N \lambda+q \mu+v \\
& M^{\prime}=N \lambda^{\prime}+q \mu^{\prime}+v^{\prime}
\end{aligned}
$$

where $\lambda, \mu, v$ and $\lambda^{\prime}, \mu^{\prime}, v^{\prime}$ are associated with $w, E I, E I^{\prime}, L$ and the connection geometric and material properties.

Furthermore, the overall equilibrium equation (Figure $2 \mathrm{~d}$ ) is given by:

$$
M^{\prime}=\frac{q L^{2}}{2}-N w-M
$$

Finally, the total axial deformation of the system can be defined quite accurately by a second order approximation:

$$
\frac{w^{2}}{2 L}=u+u^{\prime}+\frac{N}{K^{a}}
$$

- $\quad K^{\mathrm{a}}$ is the equivalent axial stiffness of the beam $(E A / L)$ and adjacent structure $\left(K_{\mathrm{s}}\right)$

- $\quad u$ and $u^{\prime}$ are the connection axial deformations which are defined in a similar fashion to the connection $M-N-\Phi$ and $M^{\prime}-N-\Phi^{\prime}$ relationships [3]:

$$
u=M \alpha_{2}+N z \beta_{2}-\gamma_{2}
$$


$u^{\prime}=M \alpha^{\prime}{ }_{2}+N z^{\prime} \beta_{2}^{\prime}-\gamma_{2}^{\prime}$

By solving the set of Eq. 1 - 5, explicit equations linking:

- the connection bending moments $\left(M, M^{\prime}\right)$ and deformations $\left(\Phi, \Phi^{\prime}\right.$ and $\left.u, u^{\prime}\right)$,

- the beam axial load $(N)$ and axial deformation $\left(\Delta_{\mathrm{s}}\right)$, and

- the beam deflection $(w)$

with the beam loading $(q)$ may be derived.

This set of equations provides an analytical method for prediction of the beam nonlinear static response. This method facilitates rapid quantitative parametric studies and assists with understanding the mechanics of the problem.

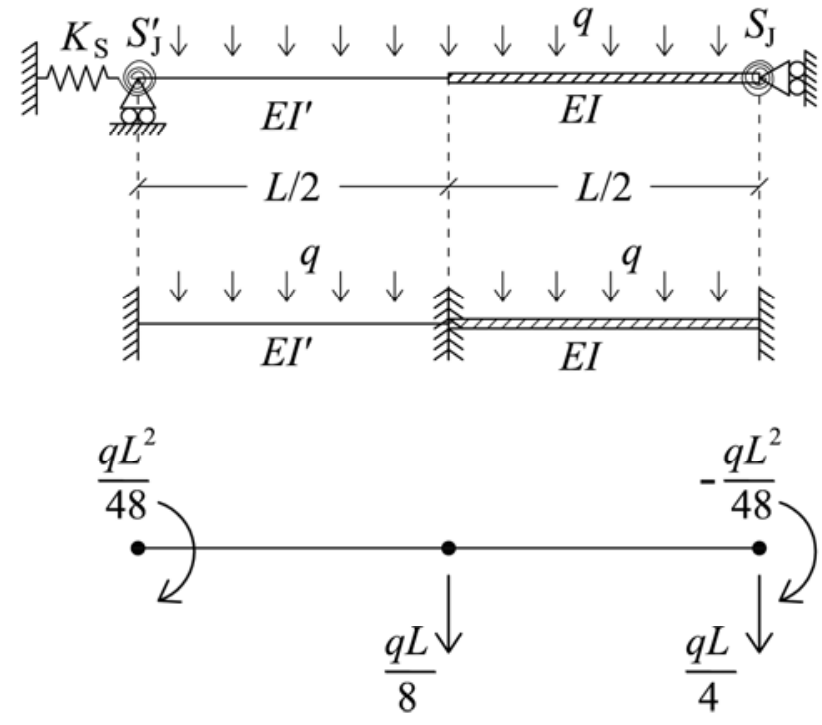

a. Equivalent clamped structure and nodal forces
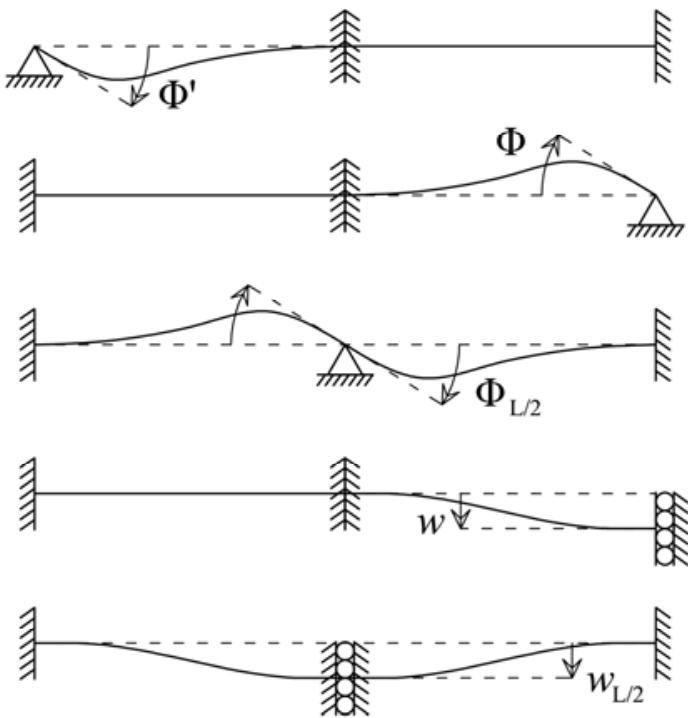

b. Basic displacement modes

Figure 4. Application of the Stiffness Method

\section{APPLICATION AND VERIFICATION OF THE SIMPLIFIED METHOD}

The simplified method described in the previous section has been applied for examination of various beam arrangements and some representative cases are presented herein. The responses of these arrangements are used in a parametric study where the interplay between the various structural parameters is explored and the most effective considerations in enhancing beam performance are identified. In addition, a second analysis has been conducted for each arrangement using the nonlinear analysis program ADAPTIC [1], with the results being used for verification of the simplified method.

\subsection{Layout of the Study}

For each of the sixteen different arrangements presented in Table 1, the nonlinear static response of the double-span beam after removal of the intermediate column as shown in Figure 2a has been determined. The full-depth flush endplate minor-axis beam-to-column connection type shown in Figure 5 has been considered, with the arrangement varying accordingly for each case (Table 1). A specific column section has been used for all the cases (Figure 5) and it has been considered as rigid, thus the column web has not been included in the connection analysis. 
Table 1. Beam Arrangements used in the Parametric Study

\begin{tabular}{|c|c|c|c|c|c|c|c|c|c|c|}
\hline $\begin{array}{c}\text { Case } \\
\text { no. }\end{array}$ & $\begin{array}{l}L \\
\text { (m) }\end{array}$ & Beam & Type & $\begin{array}{l}\text { Axial } \\
\text { restr. }\end{array}$ & $\frac{D_{p}}{(\mathrm{~mm})}$ & $\begin{array}{c}t_{p} \\
(\mathrm{~mm})\end{array}$ & $\frac{e_{1}}{(\mathrm{~mm})}$ & $\frac{p_{l}}{(m m)}$ & $\begin{array}{l}\text { bolt } \\
\text { rows }\end{array}$ & $\begin{array}{c}\text { rebar } \\
\text { no. }\end{array}$ \\
\hline 1 & 6 & UB406x140×39 & Bare steel & yes & 398 & 10 & 90 & 70 & 4 & --- \\
\hline 2 & 6 & UB406x140×39 & Composite & yes & 398 & 10 & 90 & 70 & 4 & 2 \\
\hline 3 & 6 & UB406×140×39 & Composite & yes & 398 & 10 & 90 & 70 & 4 & 4 \\
\hline 4 & 6 & UB406×140×39 & Composite & yes & 398 & 10 & 90 & 70 & 4 & 6 \\
\hline 5 & 6 & UB406×140×39 & Composite & yes & 398 & 10 & 90 & 70 & 4 & 8 \\
\hline 6 & 6 & UB406x140×39 & Composite & no & 398 & 10 & 90 & 70 & 4 & 8 \\
\hline 7 & 6 & UB406×140×39 & Bare steel & yes & 398 & 12 & 90 & 70 & 4 & --- \\
\hline 8 & 6 & UB406x140×39 & Composite & yes & 398 & 12 & 90 & 70 & 4 & 8 \\
\hline 9 & 6 & UB406×140×39 & Composite & yes & 398 & 8 & 90 & 70 & 4 & 4 \\
\hline 10 & 6 & UB305x165x40 & Composite & yes & 303 & 8 & 90 & 60 & 3 & 4 \\
\hline 11 & 6 & UB254×102×22 & Composite & yes & 254 & 8 & 70 & 60 & 3 & 4 \\
\hline 12 & 4 & UB254×102×22 & Composite & yes & 254 & 8 & 70 & 60 & 3 & 4 \\
\hline 13 & 6 & UB533×210x92 & Composite & yes & 533 & 8 & 90 & 70 & 6 & 4 \\
\hline 14 & 6 & UB533×210x92 & Composite & no & 533 & 8 & 90 & 70 & 6 & 4 \\
\hline 15 & 9 & UB610×229x101 & Composite & yes & 602 & 12 & 90 & 60 & 8 & 8 \\
\hline 16 & 9 & UB610×229x101 & Composite & no & 602 & 12 & 90 & 60 & 8 & 8 \\
\hline
\end{tabular}

By considering the first case as a starting point, the effects of various structural parameters on beam performance are explored through examination of the remaining cases (Table 1). These parameters are the beam span, the beam section, the composite action, the degree of axial restraint, the connection bare steel components and the rebar ratio.

For the composite beams, the concrete slab acts compositely with the profiled steel decking. The dimensions of these components as well as the height of the connection reinforcement within the slab are given in Figure 5 and they are considered as constant. On the other hand, the slab effective breadth varies for each case according to the beam span. The connection reinforcement bars have constant diameter and properties (Figure 5) but their number varies between 2 and 8 as shown in Table 1. Finally, full shear connection between the composite slab and the bare steel section is provided in all composite beams.

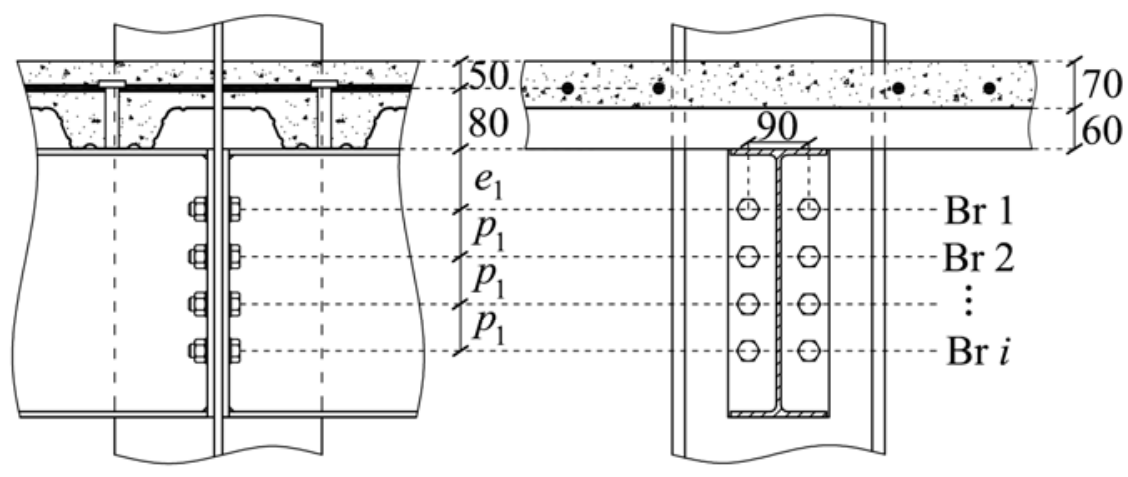

Beam [S355]: (section varies)

Column [S355]: UC305×305x118

Concrete [C30]

Rebar [S460]: $\Phi 16$

Bolts [8.8]: M20

Plate [S275]: $D_{\mathrm{p}} \times 150 \times t_{\mathrm{p}}$

$D_{\mathrm{p}}$ : plate depth

$t_{\mathrm{p}}$ : plate thickness

(Dimensions in $\mathrm{mm}$ )

Figure 5. Minor-axis Beam-to-column Flush Endplate Composite Connection Arrangement

Within a structural system the degree of beam axial restraint depends on the axial stiffness of the structure beyond the beam ends, within at least one further beam span on each side. In this respect, for the axially restrained cases, the degree of axial restraint corresponds to the equivalent axial stiffness of the beam and connection adjacent to the support connection (Figure 2). These are considered as identical to the corresponding components of the system under consideration. 
Therefore, the axial restraint is different for each case and may also vary depending on the sign of the axial load (compressive or tensile).

The resistance of the welds between the beam and the endplate has been excluded from the connection analysis. Bilinear characteristics with $1 \%$ strain hardening have been considered for the remaining tensile and rigid-plastic characteristics for the compressive components respectively. The initial stiffness and strength of these components have been determined based on the component method of EC3 and EC4.

\subsection{Application and Results}

As mentioned in Section 3, the dynamic capacity is defined based on the available connection ductility according to the Imperial College framework. For each case shown in Table 1, the connection ductility has been determined based on suitably selected connection failure criteria. For the bare steel components the failure deformation of each bolt row has been defined as the minimum between endplate bending equivalent to approximately $30 \mathrm{~mm}$ axial deformation (an average value based on experimental studies) and the deformation associated with failure of the bolts in tension. The deformation capacity of the connection reinforcement has been determined based on the model proposed by Anderson et al. [10].

The most critical component is associated with either the support or the mid-span connection of the double-span beam (Figure 2). Based on the above criteria the corresponding available rotation capacities $\theta_{1, \mathrm{f}}^{\prime}$ and $\theta_{1, \mathrm{f}}$ of the support and mid-span connection respectively are presented in Table 2 . These rotations are associated with deformations of the connection tensile components only $\left(\theta_{1}\right.$ in Figure 3). The centre of rotation for these components is the connection centre of compression as shown in Figure 3. For the support connection (region of hogging bending moment) the centre of compression is within the beam bottom flange, whereas for the mid-span connection (region of sagging bending moment) the centre of compression is within the beam top flange for bare steel or the concrete slab for composite beams.

Table 2. Structural Parameters and Beam Capacities

\begin{tabular}{|c|c|c|c|c|c|c|c|c|c|c|}
\hline $\begin{array}{c}\text { Case } \\
\text { no. }\end{array}$ & $L / D$ & $\begin{array}{c}S_{\mathrm{J}}^{\prime} \\
(\mathrm{kNm} / \mathrm{mrad}) \\
\end{array}$ & $\begin{array}{c}S_{\mathrm{J}} \\
(\mathrm{kNm} / \mathrm{mrad}) \\
\end{array}$ & $\begin{array}{c}F^{\prime}{ }_{\mathrm{Rd}}^{\mathrm{T}} \\
(k N) \\
\end{array}$ & $\begin{array}{c}F_{\mathrm{Rd}}^{\mathrm{T}} \\
(k N) \\
\end{array}$ & $\begin{array}{l}F_{\mathrm{f}, \mathrm{Rd}} \\
(k N) \\
\end{array}$ & $\begin{array}{c}\theta_{1, \mathrm{f}}^{\prime} \\
(\mathrm{mrad}) \\
\end{array}$ & $\begin{array}{c}\theta_{1, \mathrm{f}} \\
(\mathrm{mrad}) \\
\end{array}$ & $\begin{array}{c}\text { Critical } * \\
\text { component }\end{array}$ & $\begin{array}{r}q_{\mathrm{d}, \mathrm{Rd}} \\
(\mathrm{kN} / \mathrm{m}) \\
\end{array}$ \\
\hline 1 & 15.4 & 69.0 & 64.5 & 313.3 & 313.3 & 660.0 & 98.8 & 101.5 & $\mathrm{Br} 1$ '/epb & 11.3 \\
\hline 2 & 14.0 & 116.7 & 134.6 & 489.4 & 313.3 & 660.0 & 14.9 & 75.9 & Br4/epb & 17.8 \\
\hline 3 & 14.0 & 164.3 & 134.6 & 665.4 & 313.3 & 660.0 & 27.9 & 75.9 & $\mathrm{Br} 4 / \mathrm{epb}$ & 19.7 \\
\hline 4 & 14.0 & 212.0 & 134.6 & 841.5 & 313.3 & 660.0 & 29.1 & 75.9 & $\mathrm{Br} 4 / \mathrm{epb}$ & 21.5 \\
\hline 5 & 14.0 & 259.6 & 134.6 & 1017.5 & 313.3 & 660.0 & 29.9 & 75.9 & Br4/epb & 23.2 \\
\hline 6 & 14.0 & 259.6 & 134.6 & 1017.5 & 313.3 & 660.0 & 29.9 & 75.9 & Br4/epb & 21.0 \\
\hline 7 & 15.4 & 107.4 & 100.3 & 450.7 & 450.7 & 660.0 & 61.9 & 63.6 & $\mathrm{Br} 1^{1} / \mathrm{bt}$ & 13.7 \\
\hline 8 & 14.0 & 298.0 & 209.6 & 1155.0 & 450.7 & 660.0 & 29.9 & 47.6 & $\mathrm{Br} 4 / \mathrm{bt}$ & 21.9 \\
\hline 9 & 14.0 & 133.3 & 73.9 & 552.7 & 200.6 & 660.0 & 27.9 & 75.9 & $\mathrm{Br} 4 / \mathrm{epb}$ & 17.2 \\
\hline 10 & 18.0 & 76.2 & 39.0 & 508.3 & 156.2 & 754.3 & 35.5 & 98.4 & rebar & 13.2 \\
\hline 11 & 21.0 & 57.1 & 32.9 & 508.2 & 156.1 & 371.9 & 40.8 & 105.3 & rebar & 9.4 \\
\hline 12 & 14.0 & 57.1 & 32.9 & 508.2 & 156.1 & 371.9 & 42.8 & 105.3 & rebar & 21.0 \\
\hline 13 & 10.7 & 261.4 & 182.4 & 629.9 & 277.8 & 1618.9 & 18.7 & 56.1 & Br6/epb & 46.1 \\
\hline 14 & 10.7 & 261.4 & 182.4 & 629.9 & 277.8 & 1618.9 & 18.7 & 56.1 & rebar & 22.2 \\
\hline 15 & 14.3 & 842.9 & 740.6 & 1412.9 & 708.7 & 1518.9 & 18.5 & 30.2 & $\mathrm{Br} 8 / \mathrm{bt}$ & 26.2 \\
\hline 16 & 14.3 & 842.9 & 740.6 & 1412.9 & 708.7 & 1518.9 & 18.5 & 30.2 & $\mathrm{Br} 8 / \mathrm{bt}$ & 25.5 \\
\hline & & & & & & & & & reig & \\
\hline
\end{tabular}


The critical connections and the corresponding critical connection components are presented in Table 2. Provided the rotations of the support $\left(\Phi^{\prime}\right)$ and mid-span $(\Phi)$ connections vary similarly (especially beyond the elastic stage) comparison between the critical component and the rotation capacities of the tensile components $\left(\theta_{1, \mathrm{f}}^{\prime}\right.$ and $\left.\theta_{1, \mathrm{f}}\right)$ shows that the deformation of the compressive components $\left(\theta_{2}^{\prime}\right.$ and $\theta_{2}$ in Figure 3$)$ may have a significant influence on the determination of the critical connection (since $\Phi^{\prime}=\theta_{1}^{\prime}+\theta_{2}^{\prime}$ and $\Phi=\theta_{1}+\theta_{2}$ as defined in Figure 3). This is most noticeable in some of the composite beams where the ductility of the support connection is distinctly lower than the ductility of the mid-span connection but the latter fails first.

The static responses obtained by the simplified method have been converted to pseudo-static based on the simplified dynamic approach of the Imperial College method (Section 3) and the resulting dynamic capacities are presented in the last column of Table 2 . The full pseudo-static responses are presented next. The remaining parameters shown in Table 2 are used for appraisal of these responses. These parameters are the beam span-to-depth ratio $(L / D$, where $D$ is the distance between the centres of compression of the support and mid-span connections) as well as the connection stiffness $\left(S_{\mathrm{J}}^{\prime}, S_{\mathrm{J}}\right)$ and strength. The latter is given based on the connection tying capacity $\left(F^{\prime}{ }_{R d}^{\mathrm{T}}, F^{\mathrm{T}}{ }_{\mathrm{Rd}}\right)$ and the beam flange compressive resistance $\left(F_{f, R d}\right)$. The concrete flange compressive capacity is not given as it is not reached in any of these cases due to the opposite balance between the tensile and compressive capacities of the support and mid-span connections respectively of the composite beams.

\subsection{Verification and Appraisal of the Results}

The pseudo-static responses and dynamic capacities obtained from the simplified method are presented in Figures 6-8. These are compared with the corresponding ADAPTIC predictions. It is confirmed that the proposed method is able to predict the beam nonlinear static response and capacity with excellent accuracy, even for large beam deflections beyond the theoretical failure. Furthermore, the two methods of analysis exhibit excellent agreement on the prediction of the component forces and deformations and subsequently on the determination of the critical components.

Based on the results, the most important parameters have been identified and their effects are discussed next. These parameters are the connection strength, stiffness and ductility as well as the beam axial restraint and span-to-depth ratio.

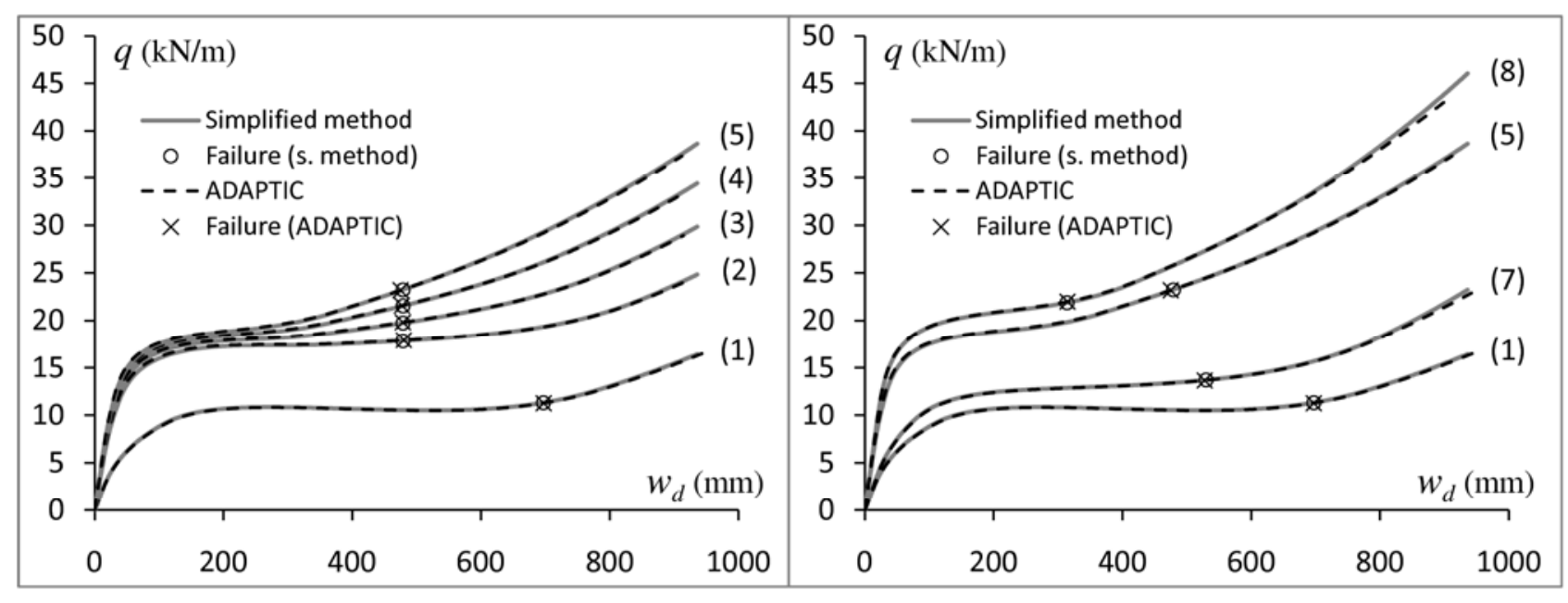

a. Reinforcement ratio

b. Endplate thickness

Figure 6. Beam p-s Responses for Various Characteristics of Connection Tensile Components 


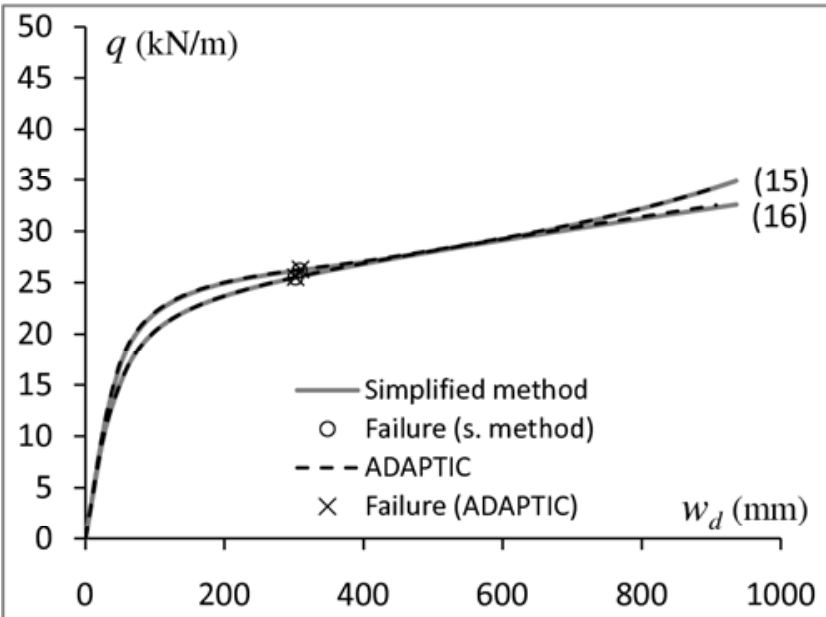

a. Limited effect of axial restraint

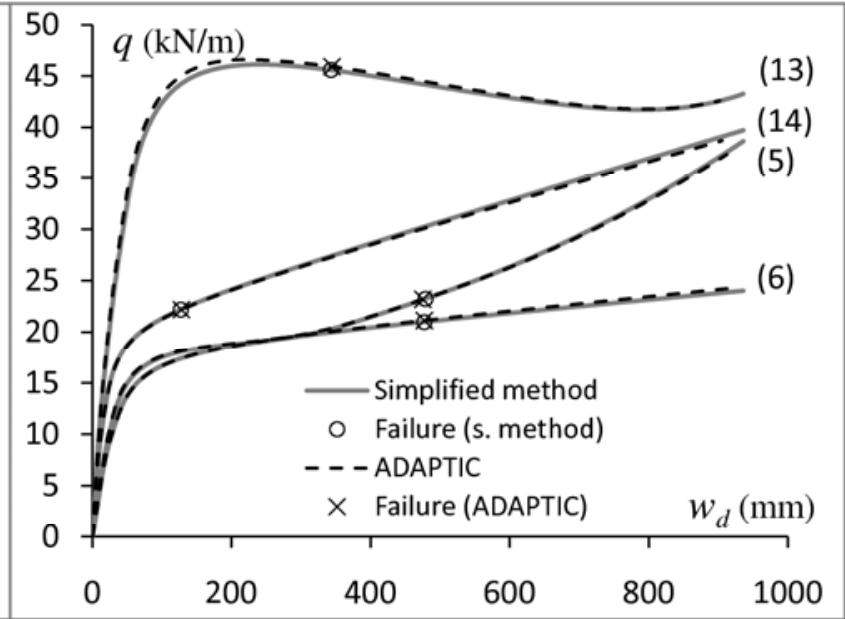

b. Substantial effect of axial restraint

Figure 7. Comparison between p-s Responses of Axially Restrained and Unrestrained Beams

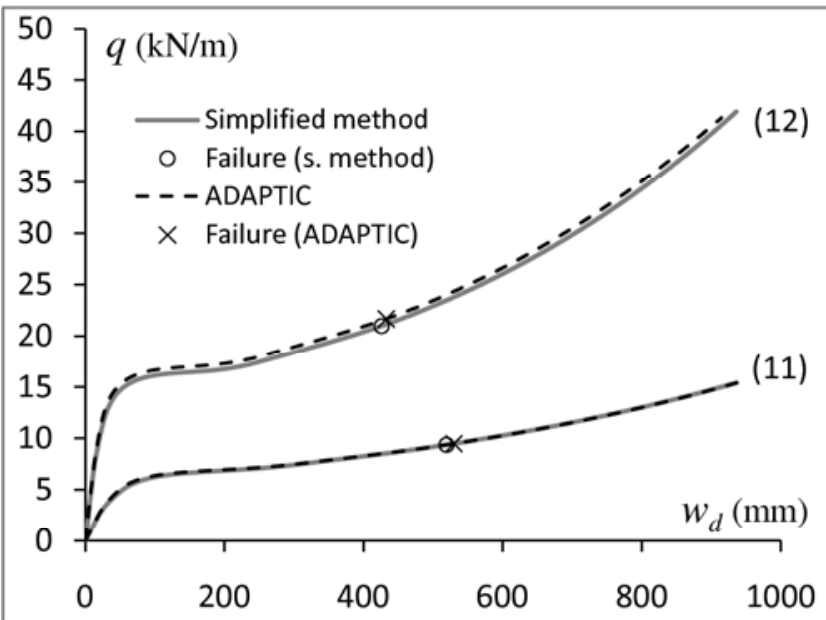

a. Different beam spans

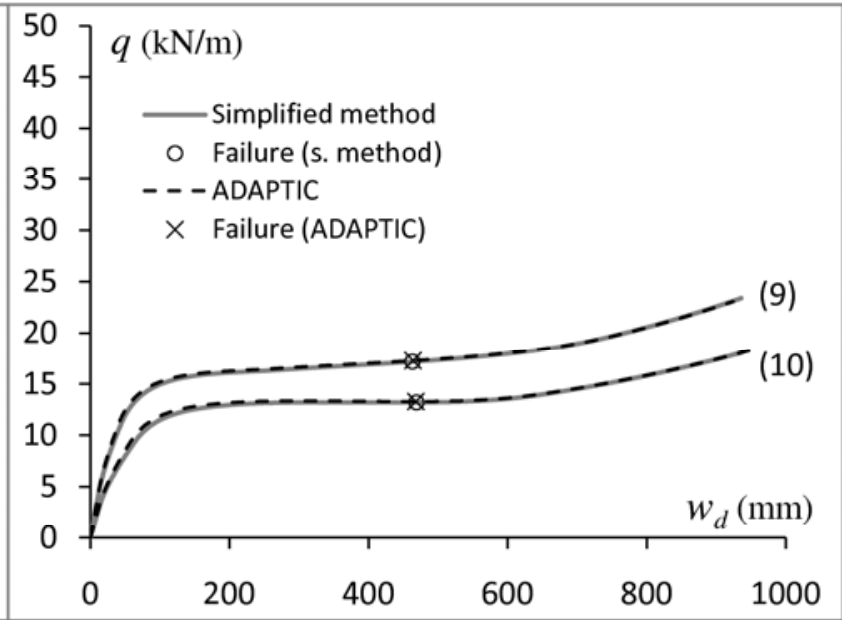

b. Different beam sections

Figure 8. Influence of the Beam Span-to-depth Ratio on the p-s Response

\subsubsection{Interplay between the Connection Parameters}

Figure 6 illustrates how the interplay between the basic connection parameters - strength (especially the balance between the tensile and compressive capacities), stiffness and ductility may influence the response and capacity of bare steel and composite beams respectively. The responses of identical composite beam arrangements with various reinforcement ratios are compared in Figure 6a whereas the effects of increasing the endplate thickness of either bare steel or composite beams are shown in Figure $6 b$.

In addition, the responses of the composite beams (cases 2-5) are compared with the response of the corresponding bare steel arrangement (case 1) in Figure 6a. The composite beams, even when the rebar ratio is relatively low as in case 2, exhibit a notably higher initial stiffness and enhanced response compared to the bare steel. This is justified mainly by the lower beam $L / D$ (higher $D$ due to higher distance between the connection centres of compression), as well as by the higher connection strengths (the strength of the mid-span connection is higher due to the higher lever arm). Another (rather less important) factor is the connection stiffness which is higher in composite beams. 
Failure is associated with the bare steel connection components for both the bare steel and composite arrangements (Table 2) but the bare steel beam exhibits a more ductile behaviour. This arises for two reasons: first, the corresponding available rotation capacity $\left(\theta_{1, \mathrm{f}}\right)$ is lower in the composite cases as shown in Table 2 due to the higher lever arms of the tensile components. In addition, the total rotation capacity $\left(\Phi_{\mathrm{f}}\right)$ of the mid-span connection (and thus the corresponding beam deflection) of the bare steel beam is higher due to higher deformation of the compressive components $\left(\theta_{2}\right.$ in Figure 3$)$.

For composite beams with different connection reinforcement ratios (cases 2-5 in Figure 6a), the mid-span connection characteristics and beam $L / D$ are the same and the differences in response are solely associated with the behaviour of the support connections. The initial responses of these arrangements are very similar and are governed by yielding of the beam bottom flange of the support connection within the compressive stage, whereas the stiffness of this connection has very limited effects at this stage as shown in Figure 6a. However, the stiffness and tensile capacity of the support connection affects the subsequent catenary stage. Especially for high reinforcement ratios (e.g. case 5) the beam axial load becomes tensile prior to yielding of the support connection tensile components and this is associated with a substantial and rather abrupt increase in response.

By increasing the endplate thickness, the connection stiffness and strength of both the mid-span and support connections increase but the ductility may decrease if the bolt capacity becomes critical in both the bare steel and composite cases ( 7 and 8) shown in Figure 6b. Therefore the response increases, but the ductility decreases and this may be followed by a decrease in capacity as shown in the composite beam response (case 8) where failure takes place within the tensile catenary stage. For the bare steel beam (case 7) on the other hand, the lower ductility is not associated with lower capacity, mainly because failure takes place before development of significant tensile catenary action.

\subsubsection{Beam Axial Restraint and Span-to-depth Ratio}

The presence of axial restraint may enhance beam performance but its effects depend on various structural parameters such as the degree of axial restraint, the beam span-to-depth ratio and the connection stiffness and strength. These parameters define the level and variation of the beam axial load generated in axially restrained beams.

Initially, the beam axial load is compressive, the connections are subjected to combined bending moment and axial load and, depending on the level of the axial load, the response may be governed by compressive arching effects. These effects increase when:

- the beam $L / D$ decreases, and/or

- the support compressive stiffness increases, and/or

- the connection compressive capacities increase (as compared to the tensile).

Whatever the level of compressive arching effects, the beam axial load subsequently becomes tensile, the connection bending moments gradually decrease and the response is governed by tensile catenary effects. If the connection compressive components remain rigid within the compressive stage $\left(\theta_{2}^{\prime}=\theta_{2}=0\right)$, the axial load becomes tensile when the beam deflection becomes equal to approximately $2 D$. On the other hand, when $\theta_{2}^{\prime}>0$ and/or $\theta_{2}>0$ within the compressive stage, the axial load becomes tensile at lower beam deflections, between 0 and $2 D$, depending on the beam $L / D$ and the connection compressive capacities $\left(F^{\prime C}{ }_{\mathrm{Rd}}, F_{\mathrm{Rd}}^{\mathrm{C}}\right)$. The tensile catenary effects increase when:

- the stiffness of the tensile components (i.e. connections, beam, support) increases, and/or

- the beam span decreases. 
The responses of various axially restrained beams are compared with the responses of the corresponding unrestrained arrangements in Figure 7. In Figure 7a, the compressive arching effects of the axially restrained beam (case 15) are limited due to the high $L / D$ and the relatively low connection compressive capacity compared to the tensile (Table 2). The axial load becomes tensile at approximately $w=D$, after yielding of the connection tensile components. For this reason, but mainly due to the long span, the tensile catenary effects are initially limited. Therefore, the presence of axial restraint barely enhances performance and the response of case 15 is similar to the response of the corresponding unrestrained arrangement (case 16).

The effects of axial restraint are stressed in Figure 7b, where the responses of two axially restrained beams governed by substantial compressive arching (case 13) and tensile catenary (case 5) effects respectively are presented.

The initial response of case 13 is notably higher compared to the corresponding axially unrestrained arrangement (case 14) due to the low $L / D$ and the high connection compressive capacity (Table 2) which increases the level of compressive axial load. The response of the corresponding axially unrestrained beam (case 14) on the other hand, is limited by yielding of the connection tensile components. Furthermore, the ductility of the unrestrained arrangement is limited by the low rotation capacity of the support connection $\left(\theta_{1, \mathrm{f}}^{\prime}\right)$, since $\theta_{2}^{\prime}$ remains zero due to the high connection compressive capacity. Regarding the axially restrained beam, the development of compressive axial load leads to yielding of the compressive components before rebar failure, the rate of increase in $\theta_{1}^{\prime}$ decreases and the ductility of the beam increases. Subsequently, the mid-span connection becomes critical as shown in Table 2 . However, any reasonable increase in ductility has no effect on capacity since the response beyond the peak of the curve is characterised by softening.

In contrast with case 13 , the response of case 5 exhibits very low compressive arching action due to the combination of high $L / D$ and low connection compressive capacity (Table 2). However, the beam axial load becomes tensile at a relatively low deflection, yielding of the tensile components of the support connection takes place within the tensile stage and the response increases significantly due to tensile catenary action. In this case, any increase in connection ductility would be very effective in increasing capacity.

Figure 8a compares identical arrangements with different beam spans. When the beam span decreases, the response increases regardless of the degree of axial restraint. The enhanced initial response of the short-span beam (case 12) compared to the response of the long-span beam (case 11) shown in Figure 8a is not associated with compressive arching effects. However, the lower span has a significant effect in the subsequent tensile stage since the catenary action depends on the beam span as mentioned before.

In Figure $8 \mathrm{~b}$, the responses of two beam arrangements with identical spans but different cross sections and connection characteristics are compared. As shown in Table 2, the deep beam (case 9) has a substantially lower $L / D$ than the shallow beam (case 10). However, the response of the deep beam is not noticeably higher than the response of the shallow beam because the latter has higher connection compressive capacity. Moreover, the two beams exhibit similar behaviour within the tensile stage since the stiffness and strength of their connection tensile components are similar and their spans are the same. 


\subsection{Concluding Remarks}

It has been established that the beam response and eventual capacity depend on the interplay between the connection parameters (tying capacity, compressive capacity, stiffness and ductility), the beam span-to-depth ratio and the degree of axial restraint. Understanding the effects of each parameter is essential for the development of effective design considerations in enhancing performance. A summary of these considerations is given next.

The response of axially unrestrained beams is analogous to the connection moment-rotation characteristics; therefore, it is most effectively enhanced by increasing the connection strength. In addition, the beam response is enhanced by increasing the connection post-limit stiffness. Therefore, any increase in connection ductility would be effective in increasing beam capacity provided the connection response is characterised by hardening. On the other hand, if the connection post-limit response is perfectly plastic governed by the resistance of the compressive components, the beam capacity is solely associated with the connection strength considering that the compressive components are relatively ductile.

The connection strength and post-limit stiffness have similar effects on the response of axially restrained beams. However, the response of axially restrained beams is enhanced compared to the response of the corresponding axially unrestrained beams due to compressive arching and/or tensile catenary actions.

Compressive arching action develops when the connection moment capacity is governed by the resistance of the tensile components and its effects depend on the connection compressive resistance, the beam axial stiffness in compression and the beam span-to-depth ratio. However, by increasing the connection compressive resistance, the compressive stage increases, the deformation of the compressive components decreases and the deformation of the tensile components increases; consequently, the possibility of development of catenary action prior to failure decreases and the capacity becomes less dependent on the connection ductility.

When the connection moment capacity of axially restrained beams is governed by the compressive components, tensile catenary action develops at relatively low beam deflections; otherwise, tensile catenary action develops after the compressive arching stage, at relatively high beam deflections. The tensile catenary effects increase by increasing the connection tensile post-limit stiffness and/or the beam axial stiffness in tension. By decreasing the compressive arching effects and enhancing the tensile catenary action the beam capacity becomes more dependent on the connection ductility.

Regardless of the above parameters, the responses of the axially restrained and unrestrained beams as well as the compressive arching and tensile catenary effects are higher for the short-span beams.

\section{PERFORMANCE OF ASSEMBLED FLOOR SYSTEMS}

By using the simplified method for prediction of the beam nonlinear static responses (Section 4) as well as the simplified dynamic method and multi-level approach of the Imperial College framework (Section 3), the progressive collapse resistance of a multi-storey building is examined herein. By considering a number of different column removal scenarios depending on the position of the initial damage within the frame, the ability of the corresponding affected floor areas to resist the redistributed loading is assessed. The resulting floor responses are appraised based on the previous observations regarding the connection and beam parameters (Section 5), whereas additional considerations associated with the performance of the assembled grillage approximation are identified. 


\subsection{Layout of the Study}

The general layout of the building is presented in Figure 1. All the floors are considered identical in terms of structure and loading; therefore the single floor model is used for the analysis. The plan view of the floor area, the floor loading and the various column removal scenarios are shown in Figure 9.

For the given layout, two different structures have been designed, considering both bare steel and composite frames, to enable comparisons between performances of the two types. For each structure, the beams have been designed by considering both the ULS and SLS conditions for the floor loading given in Figure 9. The same beam sections have been selected for all the beams in both directions of each frame as shown in Figures 10 and 11 respectively. The depths and sagging moment capacities of the bare steel and composite beams are similar (for the composite beam the concrete slab is included in the beam depth).

Full-depth flush endplate connection types have been used with the arrangements of Figures 10 and 11 for the bare steel and composite frames respectively. The composite connections have been designed for the maximum design shear force which corresponds to the transverse beams, whereas the bare steel connections have been designed based on the stiffness of the composite connections.

Because of the use of the same beam sections and in order to simplify the study, the same endplate arrangements have been considered for all the connections of each frame as shown in Figures 10 and 11. In addition, for the beam-to-column and beam-to-beam connections respectively, the columns and the supporting beams (including the weld preparations shown in Figures 10 and 11) have been considered as rigid. Thus, the resulting connection characteristics are the same for all the connections of each frame. These are presented in Tables 3 and 4. As shown in Table 3, bilinear characteristics with $1 \%$ strain hardening have been considered for the tensile and rigid-plastic characteristics for the compressive connection components respectively.

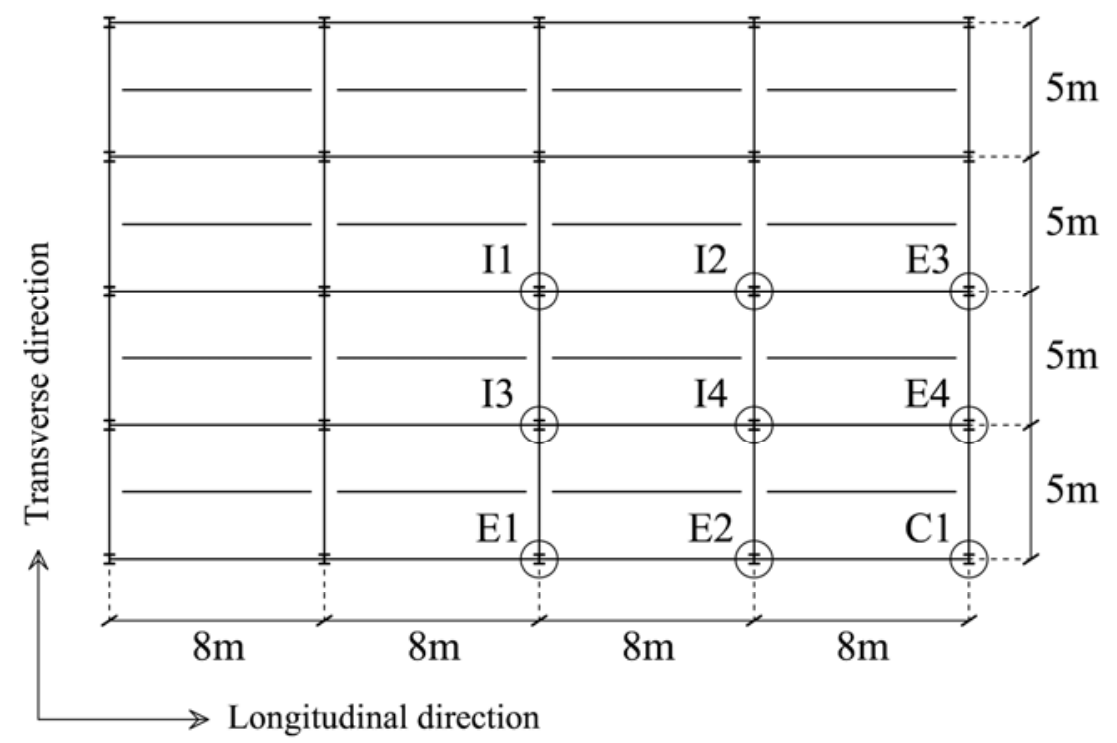

$$
\begin{aligned}
& \text { Floor unfactored loading: } \\
& \text { - Dead load: } \\
& \qquad g_{k}=4.2 \mathrm{kN} / \mathrm{m}^{2} \\
& \text { - Imposed load: } \\
& \qquad q_{k}=5.0 \mathrm{kN} / \mathrm{m}^{2} \\
& \text { I } i \text { : Removal of Internal } \\
& \quad \text { column } i \\
& \text { E } i \text { : Removal of Edge } \\
& \quad \text { column } i \\
& \text { Ci: Removal of Corner } \\
& \quad \text { column } i
\end{aligned}
$$

Figure 9. Plan View of the Floor Area and Depiction of the Various Column Removal Scenarios 


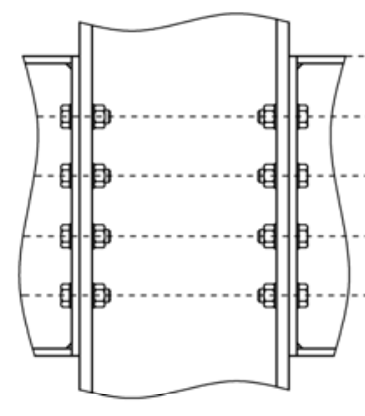

Beam-to-column major-axis

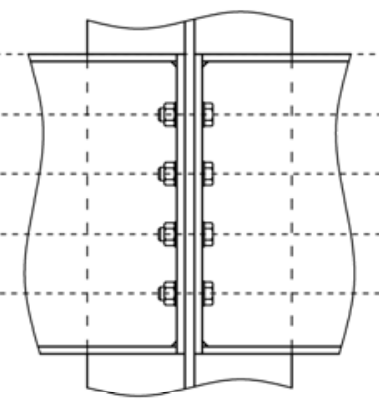

Beam-to-column minor-axis

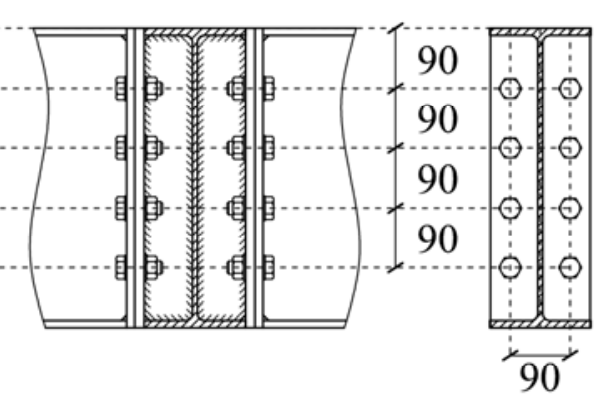

Beam-to-beam

Endplate

Beam [S355]:

UB $457 \times 152 \times 52$

Column [S355]:

UC $305 \times 305 \times 118$

Endplate [S275]:

$450 \times 150 \times 10$

Bolts [8.8]: M20

(Dimensions in $\mathrm{mm}$ )

Figure 10. Bare Steel Connections

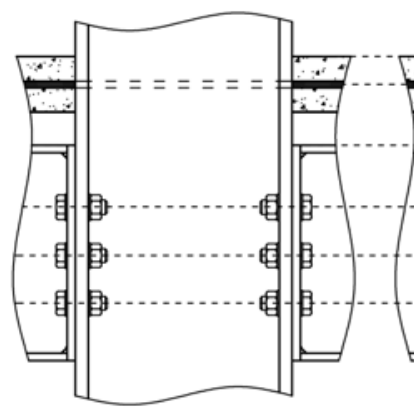

Beam-to-column major-axis

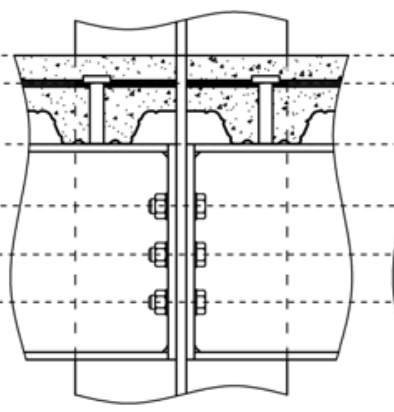

Beam-to-column minor-axis

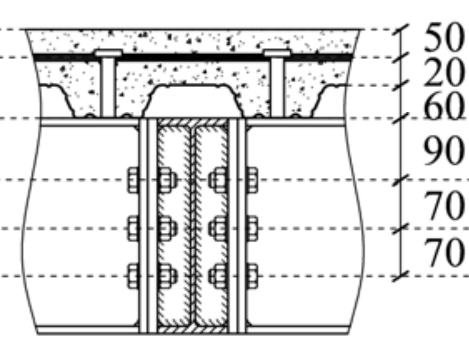

Beam-to-beam

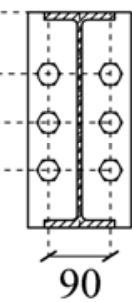

Endplate
Beam [S355]:

UB305x102x33

Column [S355]:

UC305×305x118

Endplate [S275]:

$312 \times 150 \times 10$

Bolts [8.8]: M20

Concrete [C30]

Rebar [S460]:

$4 \Phi 16$

(Dimensions

in $\mathrm{mm}$ )

Figure 11. Composite Connections

Table 3. Connection Component Characteristics

\begin{tabular}{|c|c|c|c|c|c|c|}
\hline \multirow{2}{*}{$\begin{array}{c}\text { Connection } \\
\text { components }\end{array}$} & \multicolumn{3}{|c|}{ Bare steel connection } & \multicolumn{3}{c|}{ Composite connection } \\
\cline { 2 - 7 } & $F_{\mathrm{Rd}}$ & $K^{\mathrm{e}}$ & $\mu$ & $F_{\mathrm{Rd}}$ & $K^{\mathrm{e}}$ & $\mu$ \\
\hline Reinforcement & $(\mathrm{kN})$ & $(\mathrm{kN} / \mathrm{mm})$ & $(\%)$ & $(\mathrm{kN})$ & $(\mathrm{kN} / \mathrm{mm})$ & $(\%)$ \\
\hline Bolt row 1 & 106.7 & ---- & --- & 352.1 & 424.7 & 1 \\
\hline Bolt row 2 & 70.1 & 398.4 & 1 & 98.0 & 453.9 & 1 \\
\hline Bolt row 3 & 70.1 & 346.9 & 1 & 53.8 & 266.1 & 1 \\
\hline Bolt row 4 & 106.7 & 498.5 & 1 & 99.2 & 457.0 & 1 \\
\hline Beam Flange & 886.5 & $\infty$ & 0 & --- & --- & $\cdots$ \\
\hline
\end{tabular}

Table 4. Connection Parameters

\begin{tabular}{|c|c|c|c|c|c|c|c|}
\hline $\begin{array}{c}\text { Connection } \\
\text { type }\end{array}$ & $S_{\mathrm{J}}^{\prime}$ & $S_{\mathrm{J}}$ & $F^{\prime \mathrm{T}}{ }_{\mathrm{Rd}}$ & $F_{\mathrm{Rd}}^{\mathrm{T}}$ & $F_{\mathrm{f}, \mathrm{Rd}}$ & $\theta_{1, \mathrm{f}}$ & $\theta_{1, \mathrm{f}}$ \\
\hline Bare steel & 100.9 & 101.0 & 353.5 & 353.5 & 886.5 & 84.7 & 84.6 \\
\hline Composite & 93.6 & 81.1 & 603.1 & 251.0 & 565.6 & 32.7 & 92.3 \\
\hline
\end{tabular}




\subsection{Analysis and Discussion}

The beams that are affected by edge or corner column removal when their direction is perpendicular to the corresponding edge are conservatively treated as cantilevers, ignoring the relatively low contribution of the connection in the region of sagging bending moment. On the other hand, the beams that are affected by removal of a penultimate column (I2, I4, E2 in the longitudinal and I3, I4, E4 in the transverse direction respectively) and are oriented perpendicularly to the corresponding edge are treated as axially unrestrained. The remaining beams are considered as axially restrained with the degree of axial restraint approximately defined as described in the previous section.

The beam nonlinear static responses have been obtained by the proposed simplified method and they have been converted to pseudo-static according to the simplified dynamic approach of the Imperial College framework. The floor pseudo-static response for each column removal scenario has been determined from the corresponding responses of the affected beams based on the simplified multi-level assembly approach of the Imperial College method. The pseudo-static responses of the individual beams and the resulting floor pseudo-static responses for the different column removal cases are given in Figures 12 and 13 for the bare steel and composite frames respectively. The floor capacities are associated with failure of the most critical member, whereas the beam capacities have been determined based on the failure criteria described in the previous section. The level of the vertically applied loading (Demand) at the time of column removal is $5.45 \mathrm{kN} / \mathrm{m}^{2}$, and it has been defined based on the combination of actions $g_{k}+0.25 q_{k}$ recommended by the GSA [11]. The capacity-demand ratios for the various column removal scenarios are presented in column (a) of Table 5.

For the bare steel beams, the critical component is the top bolt row of the support connection regardless of the beam span or the degree of axial restraint as shown in Figure 12a. However, the beams exhibit different levels of ductility. The ductility of the axially unrestrained and cantilever beams with identical beam spans is approximately the same. This shows that neither of the connection compressive capacities of the axially unrestrained beams has been reached before failure. The corresponding axially restrained beams on the other hand, exhibit a rather more ductile behaviour. This is associated with yielding and deformation of the compressive flanges of the support connections and a reduction in the rate of increase in $\theta_{1}^{\prime}$ as discussed in the previous section. However, since the support connections remain critical, the compressive capacities of the mid-span connections should also have been reached since $\theta_{1, \mathrm{f}}^{\prime}$ and $\theta_{1, \mathrm{f}}$ are similar as shown in Table 4. Finally, the ductility of the longitudinal beams is higher than the ductility of the transverse beams due to the longer spans; thus for any column removal scenario, the floor capacity is associated with failure of the transverse beams. This is confirmed in Figures 12b-12d.

The axially restrained bare steel beams exhibit significant compressive arching action, especially the transverse beam due to the low beam $L / D$. This is justified by the relatively high connection compressive capacity, which is substantially higher than the tensile as shown in Table 4. The responses of the corresponding axially unrestrained beams are limited by the low connection tensile capacities. 


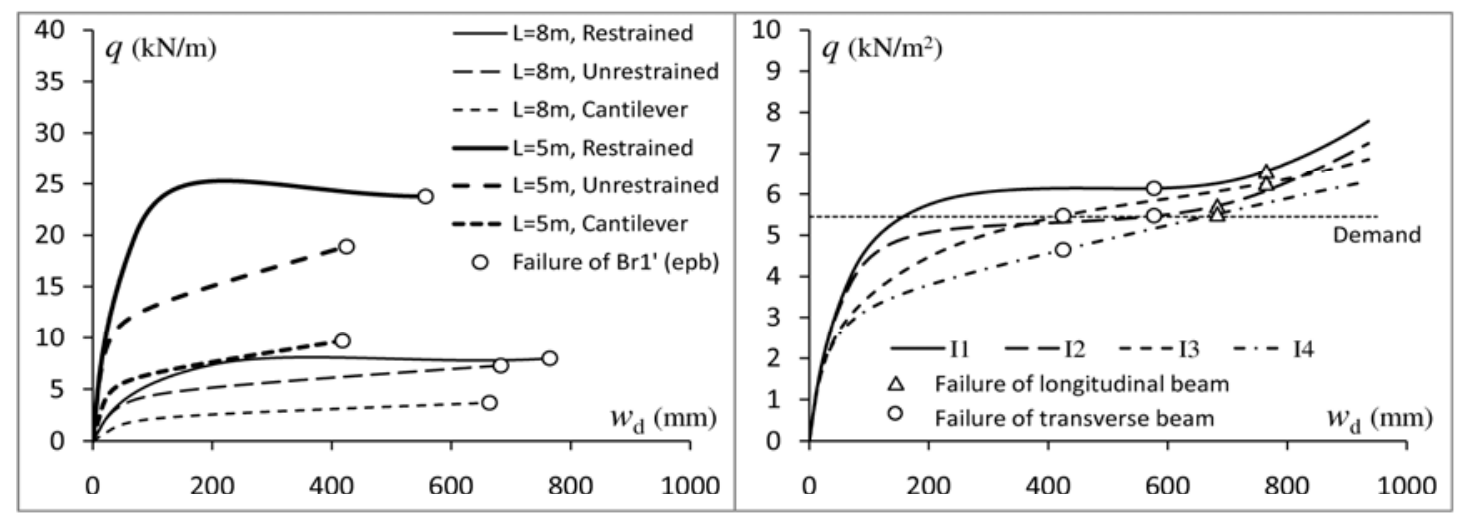

a. P-s responses of individual beams

b. Floor p-s responses - Internal column removal
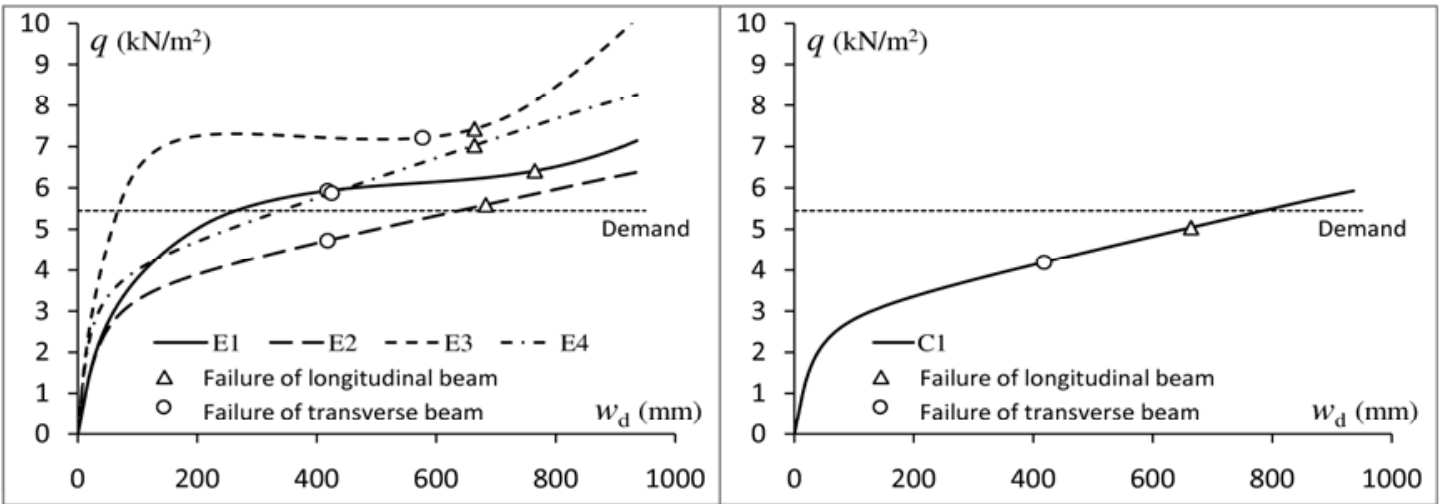

c. Floor p-s responses - Edge column removal

d. Floor p-s responses - Corner column removal

Figure 12. Progressive Collapse Assessment of Bare Steel Frame
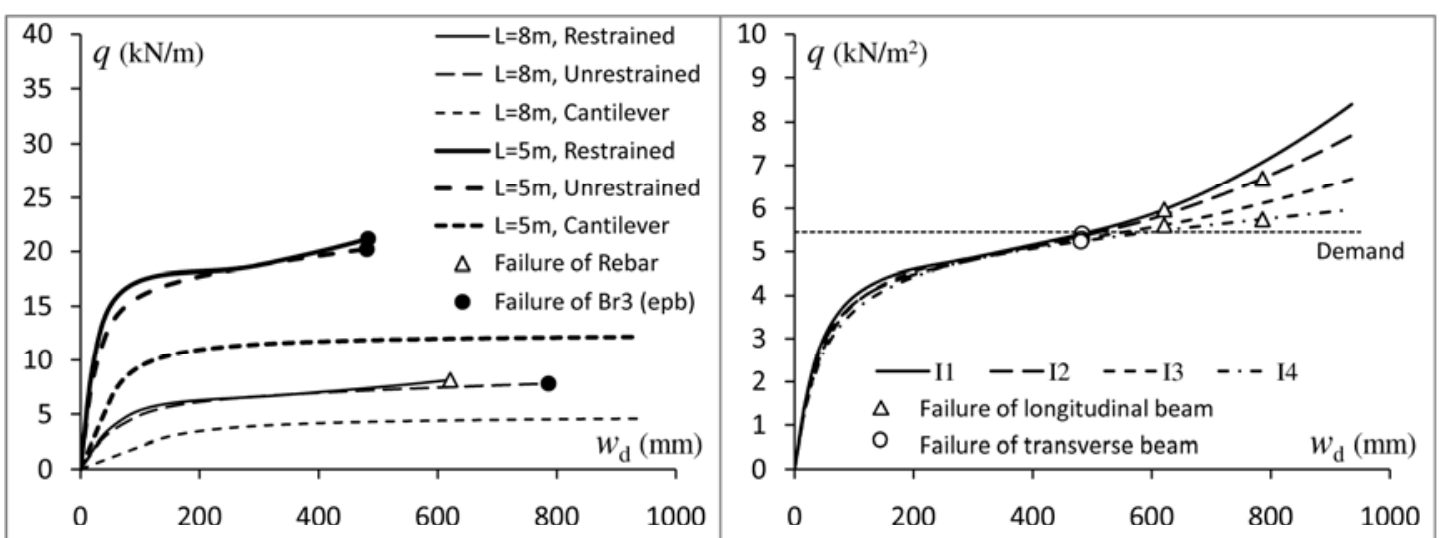

a. P-s responses of individual beams

b. Floor p-s responses - Internal column removal

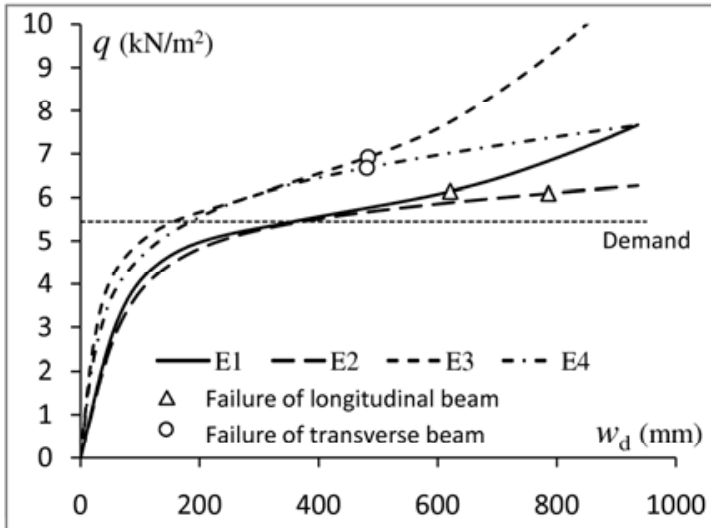

c. Floor p-s responses - Edge column removal

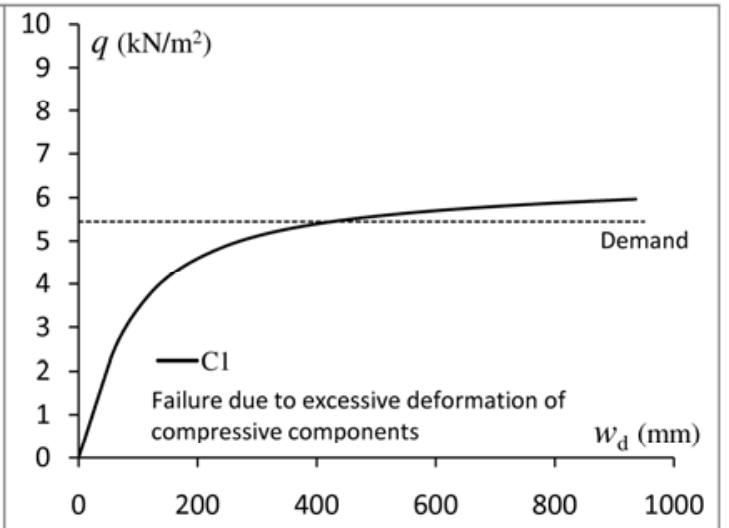

d. Floor p-s responses - Corner column removal

Figure 13. Progressive Collapse Assessment of Composite Frame 
For the composite beams, the critical component varies according to the beam span, degree of axial restraint and stiffness of the mid-span connection as shown in Figure 13a. Regardless of the span of the cantilever beams, the critical component is the beam bottom flange due to the balance between $F^{\prime T}$ Rd and $F_{\mathrm{f}, \mathrm{Rd}}$ (Table 4). For the axially restrained longitudinal beam, the critical component is the reinforcement because, for this arrangement, tensile catenary effects are developed at low beam deflections whereas the deformation of the compressive components is low due to the high beam $L / D$. This justifies the lower ductility compared to the corresponding axially unrestrained beam where the increase in rebar deformation after yielding of the support bottom flange becomes negligible and the bottom bolt row of the mid-span connection becomes critical. Similarly, for the axially restrained and unrestrained transverse beams the critical component is the bottom bolt row of the mid-span connection since the rotation of the support connection is governed by significant deformation of the bottom flange due to the low capacity of this component and the low beam $L / D$. As noted previously for the bare steel frame, the transverse beams are always the critical members as confirmed by Figures $13 \mathrm{~b}$ and 13c, except for the column removal scenarios E1, E2 and C1 where the capacities of the transverse beams are governed by yielding of the beam bottom flanges. Therefore, for the floor areas associated with column removals E1 and E2 failure is associated with the capacities of the longitudinal beams, whereas for the column removal scenario $\mathrm{C} 1$ the grillage is composed simply of cantilevers and failure is associated with the connection compressive resistances of all the beams.

The longitudinal axially restrained composite beam exhibits a similar initial response to the corresponding axially unrestrained beam due to the balance between the connection compressive and tensile capacities, whereas its response subsequently increases due to the stiffness and tying capacity of the support connection. The corresponding transverse beams behave similarly, however the effects of axial restraint are rather more pronounced due to the shorter beam span. Nevertheless, in both the axially restrained cases, failures take place prior to the development of significant catenary action.

By comparing the floor responses shown in Figures $12 \mathrm{~b}-12 \mathrm{~d}$ and $13 \mathrm{~b}-13 \mathrm{~d}$ with the responses of the corresponding affected beams, it can be established that the floor responses are similar to the responses of their most effective beams, defined as the beams that exhibit the higher responses. The bare steel floor response increases as the degree of axial restraint increases (E1, E3, I3, I2 and especially, I1). The exact opposite happens when the floor areas are axially unrestrained in both directions (E2, E4, I4) and especially when the floor is composed of cantilever beams only (C1). Furthermore, the composite floor areas with the same beam arrangements (i.e. I1-4, E1-E2 and E3-E4) initially behave almost identically regardless of the boundary conditions. These floor responses are directly related to the responses of the corresponding affected beams (Figures 12a and 13a).

The longitudinal axially restrained beams may make a substantial contribution in some cases as in the column removal scenarios I3 and E1. On the other hand, the effects of the secondary beams are limited unless they exhibit a relatively high initial response. Therefore, their contribution may be considered significant in all the composite frame cases and in the column removal scenarios I1, I3 and $\mathrm{E} 1$ of the bare steel frame.

Clearly, the responses of the bare steel floors are limited by the low stiffness and capacities of the connection tensile components whereas the responses of the composite floors are limited by the low capacities of the connection compressive components. To overcome these limitations, the connection tensile and compressive components are enhanced by increasing the endplate thickness and by stiffening the beam flanges respectively. Each modification is implemented individually in order to assess the corresponding effects on responses and capacities. The resulting beam responses 
are shown in Figures 14 and 15 and the corresponding floor capacity-demand ratios are presented in columns (b) and (c) of Table 5.

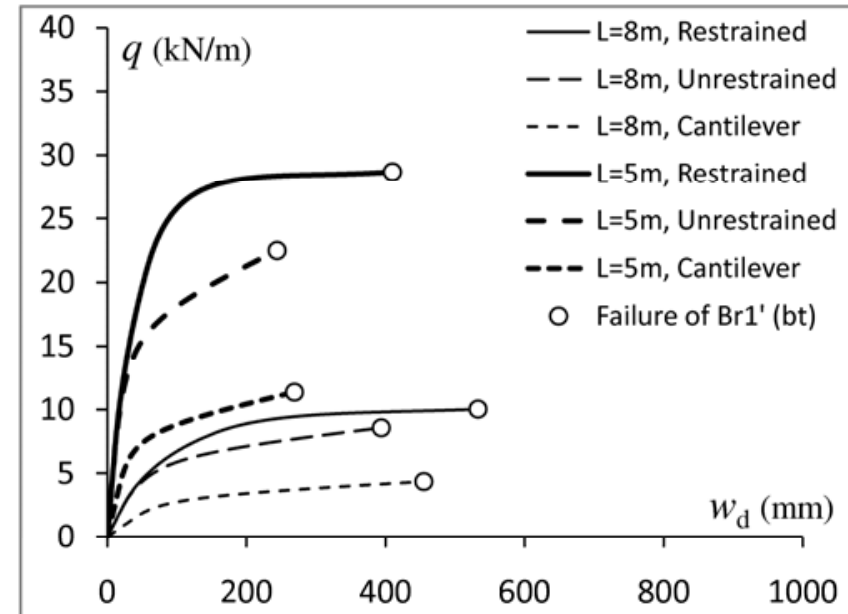

a. P-s responses of bare steel beams

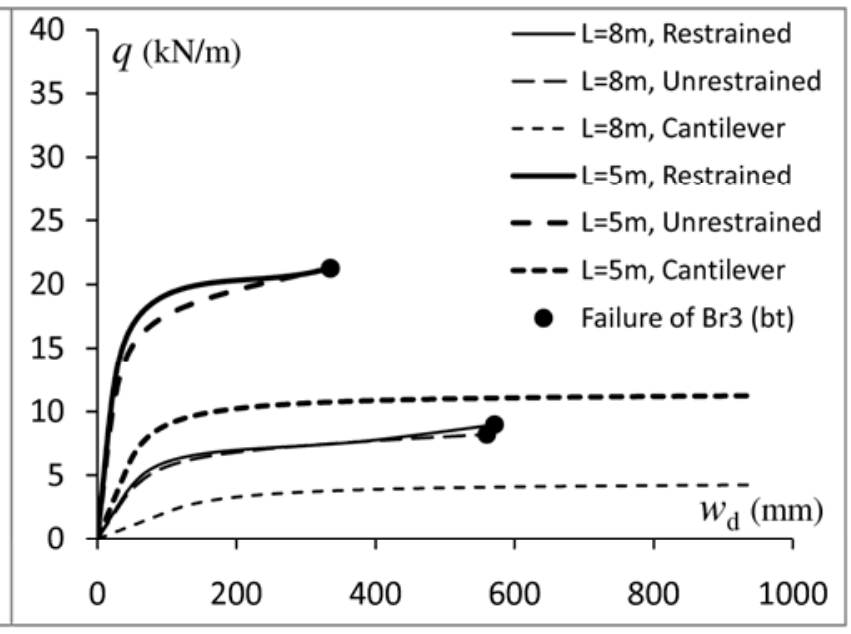

b. P-s responses of composite beams

Figure 14. Beam p-s Responses for $t_{\mathrm{p}}=12 \mathrm{~mm}$

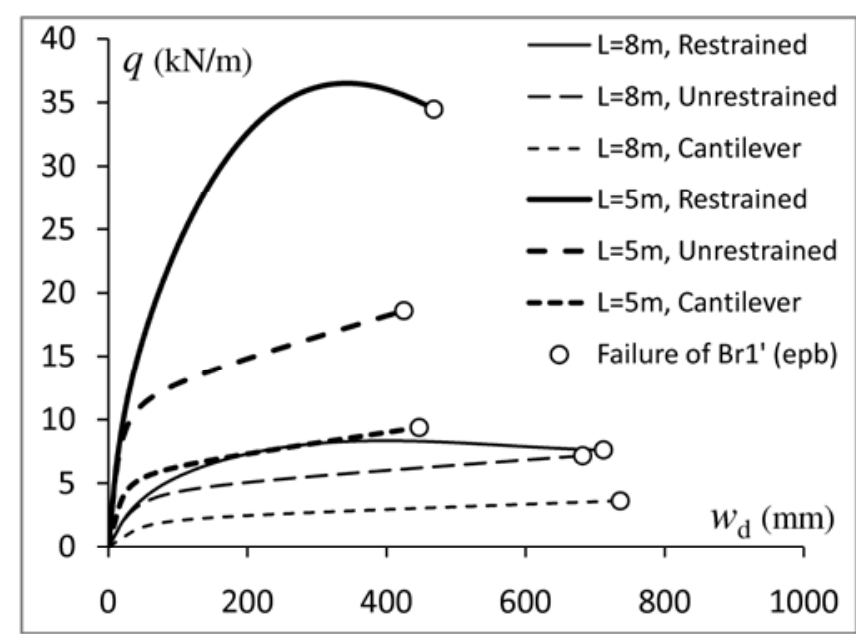

a. P-s responses of bare steel beams

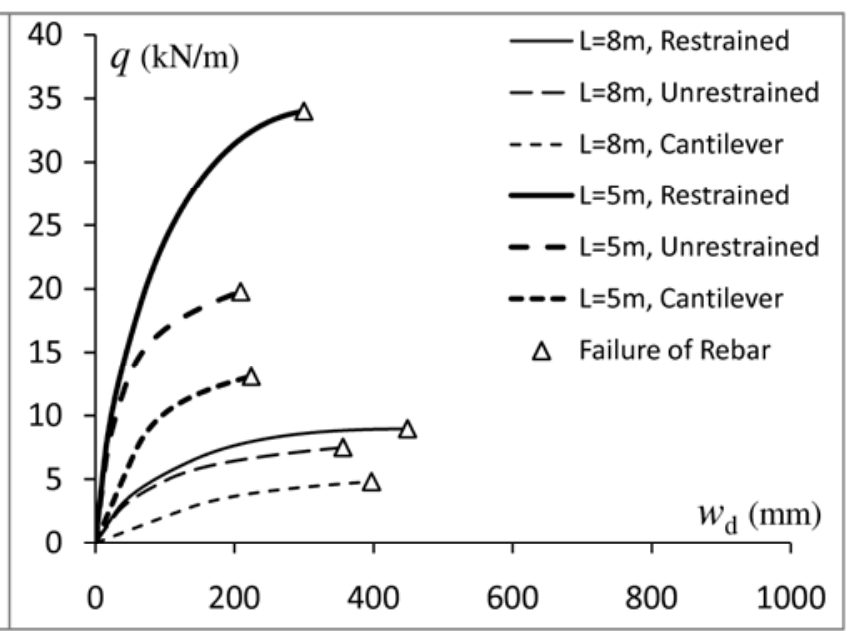

b. P-s responses of composite beams

Figure 15. Beam p-s Responses for $F_{\mathrm{f}, \mathrm{Rd}}=\infty$

Table 5. Capacity-demand Ratios for the Various Column Removal Scenarios

\begin{tabular}{|c|c|c|c|c|c|c|}
\hline \multirow{2}{*}{$\begin{array}{c}\text { Column removal } \\
\text { scenarios }\end{array}$} & \multicolumn{6}{|c|}{ Capacity-Demand ratios $\left(r=q_{\mathrm{Rd}} / q_{\mathrm{sd}}\right)$} \\
\cline { 2 - 7 } & (a) $t_{\mathrm{p}}=10 \mathrm{~mm}$, w/o FS & (b) $t_{\mathrm{p}}=12 \mathrm{~mm}, \mathrm{w} / \mathrm{F}$ FS & (c) $t_{\mathrm{p}}=10 \mathrm{~mm}, \mathrm{w} / \mathrm{FS}$ \\
\cline { 2 - 7 } & Bare steel & Composite & Bare steel & Composite & Bare steel & Composite \\
\hline $\mathrm{I} 1$ & 1.13 & 0.99 & 1.35 & 1.01 & 1.40 & 1.34 \\
\hline $\mathrm{I} 2$ & 1.00 & 0.98 & 1.23 & 1.00 & 1.23 & 1.26 \\
\hline $\mathrm{I} 3$ & 1.00 & 0.97 & 1.13 & 1.01 & 1.01 & 0.94 \\
\hline $\mathrm{I} 4$ & 0.85 & 0.96 & 1.02 & 1.00 & 0.84 & 0.88 \\
\hline $\mathrm{E} 1$ & 1.09 & 1.13 & 1.24 & 1.18 & 1.10 & 1.10 \\
\hline $\mathrm{E} 2$ & 0.87 & 1.12 & 1.06 & 1.12 & 0.86 & 0.98 \\
\hline $\mathrm{E} 3$ & 1.32 & 1.27 & 1.60 & 1.23 & 1.87 & 1.83 \\
\hline $\mathrm{E} 4$ & 1.08 & 1.22 & 1.27 & 1.23 & 1.06 & 1.12 \\
\hline $\mathrm{C} 1$ & 0.77 & 0.89 & 0.90 & 0.80 & 0.75 & 0.97 \\
\hline
\end{tabular}


By increasing the connection endplate thicknesses from 10 to $12 \mathrm{~mm}$, the bare steel and composite beam responses shown in Figures 12a and 13a respectively are modified as shown in Figure 14. As shown in Figure 14a, the responses of the axially unrestrained and cantilever bare steel beams increase but their ductility decreases due to failure of the bolts in tension (Section 5). Similarly, the ductility of the axially restrained beams decreases, but the tensile effects increase. These result in an increase of around 10-30\% in the capacity-demand ratios of the assembled floor arrangements as shown in Table 5. The highest percentages correspond to the floors governed by the responses of axially restrained or unrestrained transverse beams (i.e. I1, I2, E3 and E4), since these beams exhibit the most significant increases in response and capacity.

On the other hand, increasing the endplate thickness is not very effective in enhancing performance of the composite beams as shown in Figure 14b. There is a low increase in the responses of the axially restrained beams but the capacity barely increases due to a reduction in ductility. Moreover, the responses of the cantilever beams decrease due to the low capacities of the beam flanges. Consequently, the floor capacity-demand ratios (Table 5) either increase insignificantly or decrease if the contribution of the cantilever beams is considerable (e.g. C1 and E3).

By stiffening the beam compressive flanges, the responses of both the axially restrained bare steel and composite beams are governed by significant compressive arching effects as shown in Figure 15. These effects are considerably more pronounced in the short-span transverse beams. However, their ductility decreases since the rotations of the support connections are solely associated with deformations of the tensile components. On the other hand, there is no effect in the responses and capacities of the axially unrestrained and cantilever bare steel beams as shown in Figure 15a since, in these cases, the beam flanges remain rigid even without flange stiffening (Figure 12a). The responses of the corresponding composite arrangements increase but their ductility decreases due to rebar failure and this causes some reduction in capacities.

Therefore, by enhancing the connection compressive capacities, the bare steel and composite floor responses increase due to compressive arching action if they are governed by the responses of axially restrained beams (i.e. I1, I2 and E3 where the floor responses are governed by the responses of the axially restrained transverse beams). Thus the corresponding capacity-demand ratios increase as shown in Table 5. Otherwise, the effects of enhancing the connection compressive components are either negligible or negative depending on the corresponding effects on ductility.

\subsection{Concluding Remarks}

This study has been based on several reasonable assumptions, e.g. the use of uniform beam sections and connection characteristics, which was done so as to limit the number of different parameters involved. These assumptions and the conclusions of the previous section facilitate understanding the behaviour of the assembled grillage approximation.

It can be concluded that:

- The loading is redistributed among the remaining members depending on their individual responses.

- The overall grillage response is governed by the beams that exhibit the highest resistances.

- These are the axially restrained beams and/or the beams with the shortest spans and/or the beams that undergo the largest deflections (e.g. connected to the failed column).

- Therefore, the connection and beam parameters that govern beam responses have an analogous influence on grillage performance.

- The floor capacity is usually associated with failure of the short-span beams. 


\section{CONCLUSIONS}

It has been argued that structural engineers require design approaches to guard against progressive collapse that are essentially similar to those used for the ultimate and serviceability limit states i.e. methods that permit quantitative comparisons to be made between alternative arrangements. Further developments to the Imperial College London approach, which aims to provide such a facility, have been briefly presented. Illustrative results for different column removal scenarios for a pair of steel and composite frames have been used to illustrate the effects of different parameters. The findings confirm the complex nature of the interplay between the various physical phenomena, especially the importance of the stage in the load-deformation responses of the individual members selected as the failure criterion. A particularly important feature is whether "failure" occurs in the tensile or the compressive parts of the beam-to-column connections and whether this develops during the compressive arching or tensile membrane stage of the beam's response.

\section{REFERENCES}

[1] Izzuddin, B.A., "Non-linear dynamic analysis of framed structures", $\mathrm{PhD}$ Thesis, Department of Civil and Environmental Engineering, Imperial College, University of London, 1991.

[2] Stylianidis, P., Nethercot, D.A., Izzuddin, B.A., Elghazouli, A.Y., "Progressive Collapse: Failure Criteria used in Engineering Analysis”, Structures Congress'09, Austin, Texas, 2009, pp. 1811-1820.

[3] Stylianidis, P., Nethercot, D.A., "Representation of Connection Behaviour for Progressive Collapse Response”, Int. J. Structural Engineering, Vol. 1, No. 3-4, pp. 340-360.

[4] Izzuddin, B.A., Vlassis, G.A., Elghazouli, A.Y., Nethercot, D.A., “Assessment of Progressive Collapse in Multi-storey Buildings", Structures and Buildings, Proceedings of the Institution of Civil Engineers, 2007, Vol. 160, pp. 197-205.

[5] Izzuddin, B.A., Vlassis, G.A., Elghazouli, A.Y., Nethercot, D.A., "Progressive Collapse of Multi-storey Buildings due to Sudden Column Loss - Part I: Simplified Assessment Framework", Engineering Structures, 2008, Vol. 30, pp. 1308-1318.

[6] Vlassis, G.A., Izzuddin, B.A., Elghazouli, A.Y., Nethercot, D.A., "Progressive Collapse of Multi-storey Buildings due to Sudden Column Loss - Part II: Application", Engineering Structures, 2008, Vol. 30, pp. 1424-1438.

[7] Del Savio, A.A., Nethercot, D.A., Vellasco, P.C.G.S., Andrade, S.A., and Martha, L.F., "Generalised Component-based Model for Beam-to-column Connections including Axial Versus Moment Interaction", Journal of Constructional Steel Research, Vol. 65, pp. 1876-1895.

[8] EN 1993-1-8, Eurocode 3: "Design of Steel Structures - Part 1.8: Design of Joints", Brussels: May 2005.

[9] EN 1994-1-1, Eurocode 4: "Design of Composite Steel and Concrete Structures - Part 1.1: General Rules for Buildings", Brussels: 2004.

[10] Anderson, D., Aribert, J.M., Bode, H., Kronenburger, H.J., "Design Rotation Capacity of Composite Joints", The Structural Engineer, Vol. 78, No. 6, pp. 25-29.

[11] General Services Administration, "Progressive Collapse Analysis and Design Guidelines for New Federal Office Buildings and Major Modernization Projects”, USA, 2003. 